\title{
THE EFFECTS OF ATMOSPHERIC VARIABILITY. ON ENERGY
}

UI ILIZATION AND CONSERVATION

\author{
Progress Report Under
}

The U.S. Department of Energy

Contract DE-ASO2-76EV01340

Elmar R. Reiter, Principal Investigator

C.C. Burns, H. Cochrane, G.R. Johnson,

H. Leong, and J.D. Sheaffer

July 1980

Department of Atmospheric Science

Colorado State University

Foothills Campus; Solar House 3

Fort Collins, $C 0 \quad 80523$

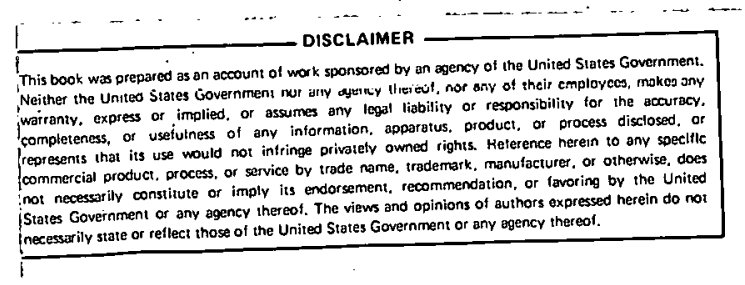

BISTRIBUTION OF THIS DOCUMEAT IS UALLMITED 


\section{DISCLAIMER}

This report was prepared as an account of work sponsored by an agency of the United States Government. Neither the United States Government nor any agency Thereof, nor any of their employees, makes any warranty, express or implied, or assumes any legal liability or responsibility for the accuracy, completeness, or usefulness of any information, apparatus, product, or process disclosed, or represents that its use would not infringe privately owned rights. Reference herein to any specific commercial product, process, or service by trade name, trademark, manufacturer, or otherwise does not necessarily constitute or imply its endorsement, recommendation, or favoring by the United States Government or any agency thereof. The views and opinions of authors expressed herein do not necessarily state or reflect those of the United States Government or any agency thereof. 


\section{DISCLAIMER}

Portions of this document may be illegible in electronic image products. Images are produced from the best available original document. 


\section{Overview}

The grant period, 1 January 1980 to 31 December 1980, covers the first year of a proposed three-year effort. Our original proposal; submitted in September 1979, was intended as a continuation proposal to research work ongoing at that time. In negotiations with the U.S. Department of Energy (DOE) it was decided, however, to redirect some of our investigations and therefore -- after extensive external review of our research goals and proposed approaches -- to commence with a new three-year effort.

As in the past, our attack on the complex problems of "effects of atmospheric variability on energy utilization and conservation" proceeded along two main avenues:

(1) Studies of large-scale feedback mechanisms within the oceanatmosphere-continent system that appear to control long-term (interannual) atmospheric variability. The ultimate goal of these efforts is to enhance our understanding of the mechanisms that control the atmosphere's general circulation and thereby to improve our long-range forecasting capabilities. Such capabilities, in the end, would be used to assess critically the weather- and climate-dependent components of energy use, to identify potential shortfalls, and to minimize their disruptive effects by designing and evaluating energy conservation strategies.

(2) Since the achievement of significant improvements in longrange forecasting skills was anticipated to be slow and, at least in part, hampered by data management problems, a simultaneous effort was launched to arrive at a thorough understanding of the weather- and climate-related components of energy demand. In the end the two avenues 
would merge to yield a forecasting capability of (regional) energy demand.

Since weather and climate affect a wide variety of energy uses, priorities had to be set in our investigation. It was decided to develop a computer model for the space-heating requirements of energy as a first tesi case of newly developed computer algorithms. The model was to be based on physical parameters, i.e. building construction characteristics, occupant use patterns, building census, measurable meteorological variables, in order to afford us the opportunity to update the model as a community expands by new construction or changes its energy demand by the adoption of conservation schemes.

As evident from our reports, this model development was highly successful. It started from an assessment of the weather-dependent energy use by individual buildings and culminated in the calculation of the daily energy demand for space heating in the city of Minneapolis, Minnesota.

Our next goal, set forth in our original three-year proposal, was to expand this community. model into a regional modelling capability. The "region" was to encompass several climatic regimes between which trade-offs in energy use might occur.

Indeed, we proceeded to explore possible data bases to be used in the development of such a regional model. Negotiations with the Public Serivce Company of Colorado (PSCC), whose service network stretches over such a multiclimate region, began to reveal some of the difficulties in data acquisition. These will be described in more detail in Section 4.2.3. Although PSCC admitted to the potential usefulness of such a regional model for short- and long-range planning purposes, the dialogue 
with a potential user made us keenly aware of another paramount energy use problem, whose weather dependent component overshadows most other concerns of regional utility planners: the increased use of energy for air conditioning during summer, and the simultaneous peak-load contribution by agricultural irrigation pumping.

The major load demand in these two use categories is on electricity, necessitating the planning and construction of new facilities in a highly inflationary market situation and at high interest costs of investment funds which, again, tend to fuel inflation as a long-term, built-in factor. Energy conservation in air conditioning and in the agricultural sector, thus, is hoped to bring a sizeable return on its investmient, perhaps more so than in other sectors of energy use.

Our original proposal anticipated a study of energy use for air conditioning, and we have already reported on some preliminary results of our study (Reiter et al., 1980, Reiter, 1980a). These results helped to stress the enormous complexity of the air conditioning problems. Most of the commercial systems which we have surveyed so far, seem to take little heed of the weather conditions outside the building. On occasion we found that different components of the system negate each other, leading to exorbitant wastes of energy. In Section 4.2 .2 we offer a more detailed description of our preliminary results.

In view of the potentially sizeable economic returns on energy conservation in air conditioning, and in view of the urgency of promoting conservation in the face of proliferating new commercial construction of fully air conditioned buildings we decided -- in agreement with our DOE sponsors -- to concentrate our major effort on the modelling of energy use for air conditioning, even at the expense of some of the other studies originally proposed. 
This progress report is structured along the four major tasks that were outlined in our proposal of September 1979:

(1) Atmosplieric circulation and climate variability

(2) Urban mesoclimate

(3) Energy demand modelling

(4) Economic implications of weather variability and energy demand: Stimulating Residential Energy Conservation Through the Financial Section.

As will become evident in the subsequent sections, some of these topics received more emphasis than others. The need for such eclecticism has been explained above. It should be mentioned, furthermore, that a delay in funding necessitated the curtailment of field operations in Greeley, Colorado (see Section 4.2.1), and the dismissal and attrition of some of our personnel. Also, a plea for more detailed documentation of our past research accomplishments, voiced by our DOE sporisors; resulted in a heavy writing commitment by most of our scientific personnel, that took up the better part of the period between November 1979 and March 1980. In retrospect, however, the consolidated writing effort could be viewed as a salutary exercise, because it helped in the fomentation of new and highly useful ideas. The exercise culminated in Environmental Research Paper No. 24, which. just now (July 1980) rolled off the press and which gives a concise overview of our results in the modelling of space heating energy demand. Preliminary results of an air conditioning study are offered as well in that report, so are several thought-provoking econometric analyses. 
2. Studies of Atmospheric Circulation and Climate Variability

Environmental. Research Paper No. 21 (Reiter, 1979) provided a summary of our. research work on shurt-term climate variability, with a major emphasis on air-sea interaction. Several new advances have been made since then and have, in part, been reported at various scientific conferences. For the sake of convenience, some of the new results are presented as conference reports and are appended to this progress report. Nevertheless, short summaries of the major findings will also be given in the subsequent sections.

\subsection{The Structure of the Hadley Cel1: A New Hypothes is}

The "heat engine" of the general circulation of the atmosphere receives its main energy input in the tropics. Time- and longitudeaveraged cross-sections through the atmosphere show the immediate effect of this energy input in the form of well-orgainzed Hadley cells (HC) whose ascending branches contain the Intertropical Convergence Zone (ITCZ) with its precipitation systems. A thorough understanding of the structure of the Hadley circulation, thus, seems to be a prerequisit to an understanding of the general circulation of the atmosphere.

Observational evidence of the vertical structure of the $\mathrm{HC}$ obtained from mean meridional cross sections and accumulated over the years by a number of investigators (see Vicent, 1968; Newell et al., 1969; review by Reiter et al., 1975) indicates a rather broad rising branch. The vertical mass flux in this ascending branch is continuous from the lower troposphere to the tropopause, and even into the stratosphere (Fig. 2.1.1). Reiter (1978) used estimates of this mass flux to assess the role of the $H C$ in tropospheric-stratospheric air-mass exchange. 


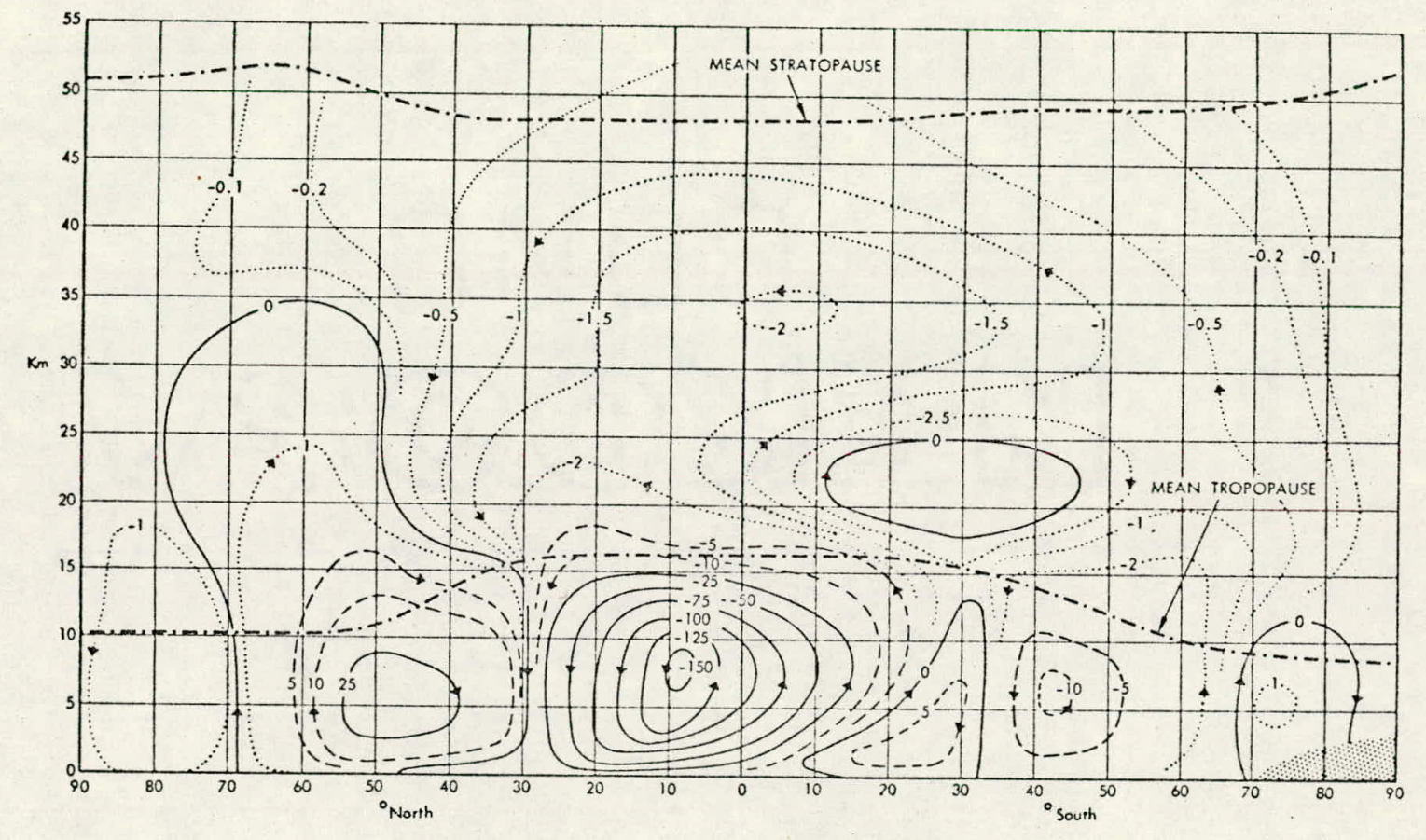

Fig. 2.1.1 Mean meridional circulation, December-February, (mass flow in units of $10^{9} \mathrm{~kg} / \mathrm{sec}$ ). Sources: above $15 \mathrm{~km}$, Louis; below $15 \mathrm{~km}$, Newell et al., 1969 (from Reiter et al., (1975). 
We know that in reality the major upward motions in the HC occur in the "hot tower" convection of the ITCZ. The rather broad band of upward motions in the tropics, cvident from Fig. 2:1.1, is a product of averaging longitudinally a narrow but meandering ITCZ.

Figure 2.1.1 induces us to the tacit assumption that convective transport would carry moisture and tropospheric trace constituents from low levels of the troposphere to the tropopause in a rather short time span of the order of one hour.

There is mounting evidence from GATE data (Murakami, 1979; Reeves, Ropelewski and Hudlow, 1979; Cheng and Houze, 1979; Arkin, 1979) and from cloud observations over Venezuela (Rieh1, 1977) that most of the convective cloud development levels off below $200 \mathrm{mb}$ and does not seem to raach the tropical tropopause which, on the average; is found near the $100 \mathrm{mb}$ level (Reiter, 1978).

What would limit the growth of average convective systems in the rising branch of the $H C$ ? Is such a "lid" on convection in the upper troposphere a characteristic feature of the Hadley circulation?

Sadler (oral communication) attributes this limitation to convective cloud growth to the vertical wind shear found in the tropics in the altitude range near the $200 \mathrm{mb}$ level, especially during winter. There should, therefore, be some mechanism in the tropical general circulation which provides for such strong shears in the upper troposphere.

Figure 2.1.2 illustrates schematically the cellular appearance of the subtropical high-pressure belt which, during winter and during the transition seasons, marks the descending branch of the HC. (During summer, the subtropical high-pressure belt is found near 20 to $30^{\circ} \mathrm{N}$ over the Pacific, but the zonally averaged vertical motion pattern indicates 


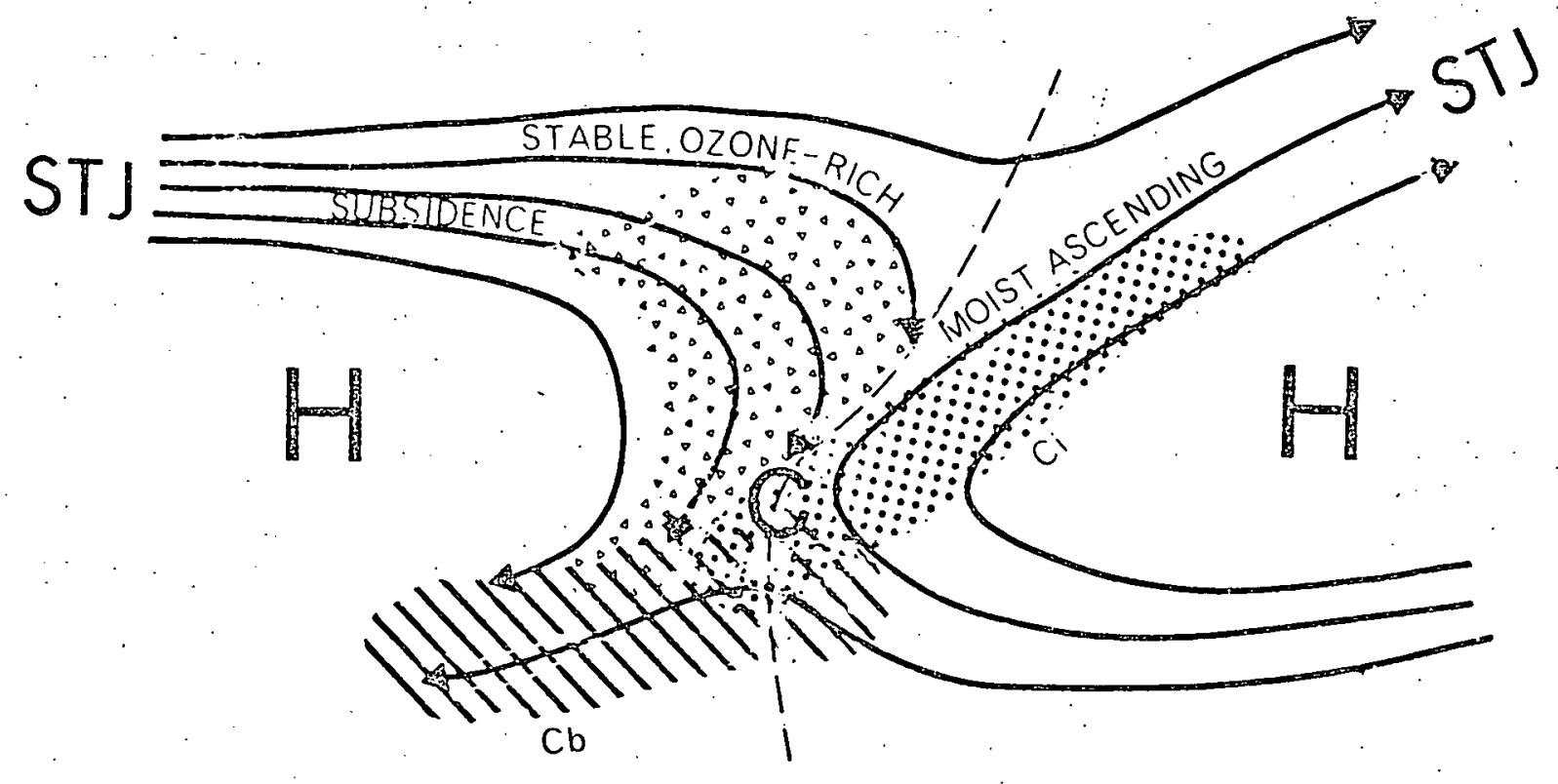

Fig. 2.1.2 Schematic upper-tropospheric map, showing the flow patterns around two subtropical anticyclonic cells. 
rising motions in this latitude region, because of the disturbing effects of the Asian monsoon circulation.) That sinking motion is mainly associated with the southward flow in the eastern portions of individual subtropical high-pressure cells. We should expect that outflow of ozone-rich stratospheric air into the tropopshere through the jet-stream front of the subtropical jet stream (STJ) occurs mainly in these regions. The yenerally barotropic structure of the subtropical atmosphere precludes a rapid sinking of this ozone-rich air to the ground, dissimilar to what is observed near polar-front jet (PFJ) maxima. Instead, the sinking air tends to undergo horizontal spreading and stabilization in the upper troposphere as it is entrained into the upper-tropospheric equatorial easterlies under quasi-conservation of absolute angular momentum.

Danielsen (1980), using "Gametag" data, confirmed the presence of ozone intrusions within air masses of stratospheric origin that traveled near the $325^{\circ} \mathrm{K}$ isentropic surface around the eastern edge of a subtropical high pressure cell located in the central North Pacific near $30^{\circ} \mathrm{N}$. These air masses curved sharply anticyclonically as they entered the upper troposphere, as schematically indicated in Fig. 2.1.2. High ozone concentrations were encountered by aircraft somewhat to the northeast of Hawaii at flight levels between 5.4 and $\sigma \mathrm{km}$. It should be noted that similar extrusions of ozone-rich siratospheric air into the troposphere associated with the wintertime PFJ are usually centered near the $310^{\circ} \mathrm{K}$ isentropic surface.

To the east of the col "C" in Fig. 2.1.2 we find southeasterly flow from the tropics, emerging from a region of suppressed cloud development and entraining into another STJ maximum further to the east. This 
entrainment follows a path of rising motion, often associated with a! tus- and cirrus-cloud development characteristic of STJ maxima. Thus, an appearance is given of a continuous cloud band emerging from the ITCZ and connecting the tropics with midlatitude jet-stream systems. Such bands are observed frequently over the East Pacific, entering the North American continent over Baja California, and over the equatorial central Allantic continuing into the STJ over North Africa.

Sometimes the midlatitude troughs interact with easterly waves in the tropics. Such interaction is also indicated schematically in Fig. 2.1.2. Deep convection slightly ahead of, and in the easterly trough, (Thompson et al., 1979) together with the aforementioned cirrus bands extending into midlatitudes, often give the impression on satellite photographs that continuous. cloud bands extend from equatorial regions into temperate latitudes. Time-lapse pictures reveal, however, that the tropical clouds move westward, the subtropical cloud bands, on the other hand, move eastward.

The subsiding, ozone-rich air which moves southward around the eastern edge of the subtropical high-pressure cell will provide the hypothesized upper-tropospheric "lid" to convective activity that occurs in the tropical easterly wave. Also, the southward moving air, by tending to conserve absolute angular momentum, will acquire a strong easterly velocity component, giving rise to the vertical wind shears mentioned by Sadler (see also Thompson et al., 1979):

Taking into account the complex flow processes described above we arrive at the hypothetical meridional cross-section through a "typical" segment of the HC shown in Fig. 2:1.3.' The northeasterly subsiding flow, and the southwesterly ascending flow in the upper troposphere will 


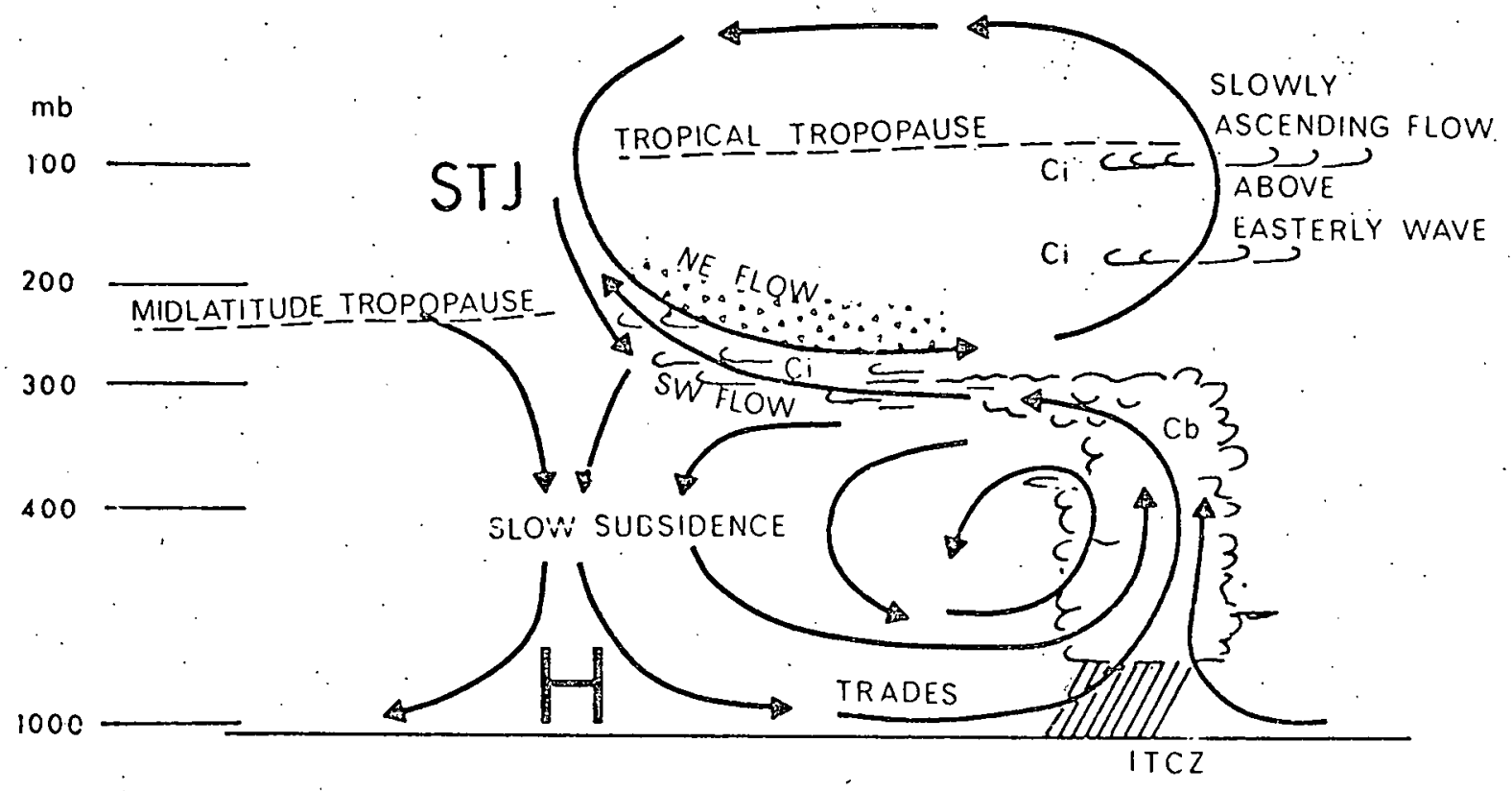

Fig. 2.1.3 Schematic cross-section through a typical portion of the northern hemisphere Hadley cell. For explanation see text. 
cancel their meridional velocity components under a zonal averaging procedure. After such averaging, the mean Hadley circulation shown in Fig. 2.1.1 remains. The horizontal eddy structure of the HC indicated in Fig. 2.1.2 is, however, an important ingredient of the subtropical general circulation, leading to the strong, but opposing meridional flow components in the middle and upper troposphere, sketched in Fig. 2.1.3.

We have persuaded the Los Alamos Scientific Laboratory (Dr. W.A. Sedlacek) to conduct chemical sampling flights in the upper troposphere of the subtropics and tropics to check the validity of the hypothetical "double-yolked" structure of the HC. Should this hypothesis prove to be correct, it might force a reevaluation of upper tropospheric photochemistry and its effect on stratospheric trace substances, since tropospheric residence times of several days may have to be postulated in the slowly rising motions of the upper troposphere above the ITCZ, before these air. masses enter the stratosphere -- as opposed to the short residence time of the order of less than one hour within the tropical convective systems. Furthermore, some of the air involved in the upper "yolk". of the double-structured HC may contain significant amounts of $\mathrm{O}_{3}$ which could enter into photochemical reactions with other tropospheric trace constituents.

\subsection{Long-Term Variability of Tropical and Subtropical Circulation Systems}

In the foregoing section we have dealt in rather general terms with some of the structural peculiarities of the Hadley circulation. Reiter (1979) pointed out that there exists a rather significant interannual variability of this circulation, evident from variations in the convergence between the space- and time-averaged $v$-components of the surface winds in the northern and southern hemisphere trade-wind belts. In 
the Pacific longitude sector this convergence is positively correlated to excessive precipitation in the so-called "dry zone" of the equatorial Pacific, stretching across Nauru, the Line Islands, to the Peruvian. coast.. Strong positive peaks in precipitation anomalies are accompanied by El Niño events, as revealed by coastal sea-surface temperature (SST) aniomalies. Specturm analyses of equatorial precipitation Pacific tradewind convergence, and Peruvian SST anomalies suggest a rather broad spectral peak between 3 and 4 years. In the Atiantic sector, on the other hand, a quasi-biennial oscillation (QBO) appears in the surface trade-wind convergence, which seems to be related to the $Q B O$ in the equatorial stratospheric wind system (Reiter, 1979).

Equatorial and subtropical SST anomalies seem to be involved in feedback mechanisms that modulate the $H C$ intensity. We have postulated (Reiter, 1979) that such modulations involve in an important way the hydrological cycle which, to a significant degree, helps to drive the general circulation of the atmosphere by the release of latent heat in equatorial and monsoonal precipitation systems.

Since the energy budget of tropical storms relies mainly on the release of latent heat, and since the frequency of these storms shows considerable interannual variability, we decided to embark on a detailed investigation of the possible factors influencing this variability. Our first target was the tropical storm activity in the Pacific. A similar study for Atlantic hurricanes is in its preliminary stage.

Detailed reports of our findings have either been issued, or are in the final stage of preparation (Ding and Reiter, 1980a, 1980b, 1980c, 1980d). The major results are summarized in Table 2.2.1. It appears that Hadley and Walker circulation intensities significantly affect 
Table 2.2.1 The major differences in circulation features between months with many and with few typhoon months.

\begin{tabular}{|c|c|c|c|}
\hline \multicolumn{2}{|c|}{ Circulation Features } & Months with Many & Months with Few \\
\hline \multirow{6}{*}{$\begin{array}{l}\text { Lower } \\
\text { Level }\end{array}$} & ITCZ & $\begin{array}{l}\text { Very strong and ex- } \\
\text { tended. }\end{array}$ & $\begin{array}{l}\text { Very weak or non- } \\
\text { existent. }\end{array}$ \\
\hline & $\begin{array}{l}\text { Monsoon trough } \\
\text { over India. }\end{array}$ & $\begin{array}{l}\text { Northward advance to } \\
\text { Himalayas. }\end{array}$ & $\begin{array}{l}\text { Very obvious and } 10^{-} \\
\text {cation in the north- } \\
\text { ern part of the } \\
\text { Indian peninsula. }\end{array}$ \\
\hline & SW monsoon. & $\begin{array}{l}\text { Monsoon break in India, } \\
\text { eastward extension of } \\
\text { strong monsoon over } \\
\text { the West Pacific }\end{array}$ & $\begin{array}{l}\text { Active monsoon in } \\
\text { India, very weak } \\
\text { over the West Pacific }\end{array}$ \\
\hline & $\begin{array}{l}\text { Position of sub- } \\
\text { tropical high } \\
\text { over the Pacific }\end{array}$ & $30^{\circ} \mathrm{N}$ & $25^{\circ} \mathrm{N}$ \\
\hline & $\begin{array}{l}\text { Somalia low level } \\
\text { jet: }\end{array}$ & Strong & Weak \\
\hline & $\begin{array}{l}\text { Cross-equatorial } \\
\text { airflow over the } \\
\text { West Pacific }\end{array}$ & Strong & Weak \\
\hline \multirow{7}{*}{$\begin{array}{l}\text { Upper } \\
\text { Level }\end{array}$} & $\begin{array}{l}\text { TUTT } \\
\text { Tropical upper- } \\
\text { tropospheric } \\
\text { Trough }\end{array}$ & $\begin{array}{l}\text { Eastward shift to the } \\
\text { region east of } 180^{\circ}\end{array}$ & $\begin{array}{l}\text { Westward shift to } \\
160^{\circ} \mathrm{E}\end{array}$ \\
\hline & $\begin{array}{l}\text { Upper easteriy } \\
\text { jet }\end{array}$ & $\begin{array}{l}\text { Strong over the West } \\
\text { Pacific, weak over the } \\
\text { Arabian Sea }\end{array}$ & $\begin{array}{l}\text { Weak over the West } \\
\text { Pacific, strong over } \\
\text { the Arabian Sea }\end{array}$ \\
\hline & Tibetan high & $\begin{array}{l}\text { Eastward shift to about } \\
100^{\circ} \mathrm{E}\end{array}$ & $\begin{array}{l}\text { Over the Tibetan } \\
\text { Plateau }\end{array}$ \\
\hline & $\begin{array}{l}\text { Subtropical } \\
\text { westerly jet over } \\
\text { central and east- } \\
\text { ern Pacific, N.H. }\end{array}$ & Strong & Weak \\
\hline & $\begin{array}{l}\text { Polar-front } \\
\text { westerly jet a- } \\
\text { round } 40^{\circ} \mathrm{N} \text { in } \\
\text { N.H. }\end{array}$ & Weak & Strong \\
\hline & $\begin{array}{l}\text { Westerly jet in } \\
\text { S.H. }\end{array}$ & Strong & Weak \\
\hline & $\begin{array}{l}\text { Cross-equatorial } \\
\text { airflow over the } \\
\text { West Pacific }\end{array}$ & Strong & Weak \\
\hline
\end{tabular}


Table 2.2.1 (Continued)

\begin{tabular}{|c|c|c|c|}
\hline \multicolumn{2}{|c|}{ Circulation Features } & \multirow{2}{*}{$\begin{array}{l}\text { Months with Many } \\
\text { Typhoons } \\
\begin{array}{l}\text { Weak and situated over } \\
\text { the Atlantic side. }\end{array}\end{array}$} & \multirow{2}{*}{ 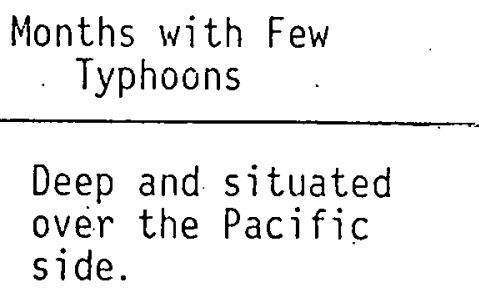 } \\
\hline \multirow{8}{*}{1} & Polar vortex & & \\
\hline & $\begin{array}{l}\text { Long wave } \\
\text { patterns }\end{array}$ & $\begin{array}{l}\text { Long wave ridge or block- } \\
\text { ing high over the eastern } \\
\text { Pacific with deep long } \\
\text { wave trough and cyclonic: } \\
\text { activity over either } \\
\text { side of the long wave } \\
\text { ridge, i.e. over } \\
\text { Kamchatka and Canada }\end{array}$ & $\begin{array}{l}\text { Long wave trough over } \\
\text { the eastern Pacific } \\
\text { with long wave ridges } \\
\text { over either side of } \\
\text { it. Cyclonic activ- } \\
\text { ity moves southward, } \\
\text { off the eastern } \\
\text { coast of Asia }\end{array}$ \\
\hline & $\begin{array}{l}\text { Circumpolar } \\
\text { westerlies }\end{array}$ & $\begin{array}{l}\text { Expands and move } \\
\text { southward }\end{array}$ & $\begin{array}{l}\text { Contract and move } \\
\text { northward }\end{array}$ \\
\hline & $\begin{array}{l}\text { Subtropical } \\
\text { high over the }\end{array}$ & $\begin{array}{l}\text { Higher-than-normal posi- } \\
\text { tion. }\left(30^{\circ} \mathrm{N}\right) \text { weak. } \\
\text { Main body situated over } \\
\text { the central Pacific }\end{array}$ & $\begin{array}{l}\text { Lower-than-normal } \\
\text { position }\left(25-27^{\circ} \mathrm{N}\right) \\
\text { strong. Remarkably } \\
\text { westward extension } \\
\text { of the main body } \\
\text { over the West Pacific }\end{array}$ \\
\hline & $\begin{array}{l}\text { Circulation } \\
\text { features at } \\
500 \mathrm{mb} \text { over } \\
\text { Tibet }\end{array}$ & $\begin{array}{l}\text { Upper trough or low- } \\
\text { pressure region }\end{array}$ & $\begin{array}{l}\text { No low pressure } \\
\text { detectable or high } \\
\text { pressure region }\end{array}$ \\
\hline & $\begin{array}{l}\text { Monsoon } \\
\text { circulation } \\
\text { systems over } \\
\text { India }\end{array}$ & $\begin{array}{l}\text { Weak monsoon troughs at } \\
500 \text { mb and surface over } \\
\text { the Indian peninsula. } \\
\text { Higher-than-normal } \\
\text { monsoon rainfall over } \\
\text { northern India. Mon- } \\
\text { soon trough extends } \\
\text { into the West Pacific }\end{array}$ & $\begin{array}{l}\text { Strong monsoon trough } \\
\text { at } 500 \mathrm{mb} \text { and surface } \\
\text { over the Indian pen- } \\
\text { insula. Higher-than- } \\
\text { normal monsoon rain- } \\
\text { fall over the } \\
\text { peninsula. Monsoon } \\
\text { trough confined with- } \\
\text { in the region west } \\
\text { of } 120^{\circ} \mathrm{E}\end{array}$ \\
\hline & $\begin{array}{l}\text { Central and } \\
\text { eastern Pacific } \\
\text { SST }\end{array}$ & $\begin{array}{l}\text { Abnormally warm water, } \\
\text { especially over the } \\
\text { equatorial East Pacific }\end{array}$ & $\begin{array}{l}\text { Abnornally cold } \\
\text { water }\end{array}$ \\
\hline & $\begin{array}{l}\text { Western } \\
\text { Pacific SST }\end{array}$ & $\begin{array}{l}\text { Abnormally cold water } \\
\text { water }\end{array}$ & $\begin{array}{l}\text { Abnormally } \\
\text { water }\end{array}$ \\
\hline
\end{tabular}


Table 2.2:1 (Continued)

\begin{tabular}{|c|c|c|}
\hline Circulation Features & $\begin{array}{l}\text { Months with Many. } \\
\text { Typhoons }\end{array}$ & $\begin{array}{l}\text { Months with Few } \\
\text { Typhoons }\end{array}$ \\
\hline $\begin{array}{l}\text { Kuroshio } \\
\text { warm current } \\
\text { SST }\end{array}$ & Abnormally warm water & $\begin{array}{l}\text { Abnormally } \\
\text { cold water }\end{array}$ \\
\hline $\begin{array}{l}\text { SST in region } \\
\text { from Japan to } \\
\text { the western } \\
\text { coast of North } \\
\text { America north } \\
30^{\circ} \mathrm{N}\end{array}$ & $\begin{array}{l}\text { Warm water band. Cold } \\
\text { water band is in sub- } \\
\text { tropics between the } \\
\text { above two warm water } \\
\text { regions }\end{array}$ & $\begin{array}{l}\text { Cold water band. } \\
\text { Warm water band } \\
\text { is in subtropics } \\
\text { between the } \\
\text { above two cold. } \\
\text { water regions }\end{array}$ \\
\hline $\begin{array}{l}\text { SST patterns } \\
\text { during anti- } \\
\text { cedent season }\end{array}$ & $\begin{array}{l}\text { Similar to the patterns } \\
\text { for summer. }\end{array}$ & $\begin{array}{l}\text { Similar to the } \\
\text { patterns for } \\
\text { summer }\end{array}$ \\
\hline
\end{tabular}


tropical storm activity. Their interannual variability not only is tied to SST anomaly patterns, but to far-reaching teleconnections whose implications we have barely begun to sludy. Even our preliminary research results have convinced us, however, that major interannual adjustments in the amplitudes, positions and stationarity characteristics of long and ultralong planetary waves provide the basic link between the observed "teleconnections". A better understanding of the response of these waves to changing patterns of forcing mechanisms should provide us with the long-sought basis for improved long-range forecasts that could be applied to energy-demand projections.

\subsection{Planetary Wave Characteristics}

Planetary waves can be described in terms of their wave numbers, their amplitudes, their phase angles (trough and ridge positions as a function of longitude), and the relative stationarity or non-stationarity of these positions from day-to-day. In a recent paper given at the Second Symposium on Arctic Air Chemistry, Reiter (1.980b) presented a preliminary study of such wave characteristics and tried to apply it to problems of air pollution transport from midlatitudes into the Arctic regions. (See Appendix A for an abbreviated copy of that report.)

The significant interannual variability which had been noted in the parameters characterizing mean daily amplitudes and stationarity indices of ultralong and long planetary waves has to have its reason in a variability of the mechanisms forcing these waves. If one accepts the idea that orographic effects and the distribution of continental, oceanic and internal heat sources and sinks provide the major forces that control the quasi-stationary planetary waves, the "resonance" or "nonresonance" configuration of such forcing parameter distributions becomes of 
paramount interest. Indeed, it appears that some of the teleconnections between SST anomalies, typhoon frequencies, polar vortex stability, etc. can be attributed to reedback processes between flow characteristics of the atmosphere on scales characterized by planetary waves and the distribution of orographic and thermal forcing patterns. A preliminary report was given by Reiter at a recent symposium in Beijing (Reiter and Ding, 1980). A copy of that report is attached as Appendix B. It will be the first paper since the Revolution to appear in English language in the Scientia Atmospherica Sinica.

A travel report, to be issued by Reiter (1980c) and detailing his experiences in China and Tibet, points out the geophysical model experiments conducted by the Academia Sinica. These experiments are intended to study the joint effects of orographic and thermal effects on planetary-wave formation.

Our own efforts are presently geared to provide an input data set for thermal forcing of atmospheric planetary wave patterns and their interannual variability. This data set, together with computations of orographic forcing, will be used in a truncated spectral model of the general circulation which is presently being developed. This model is intended to test some of the ideas expressed in Appendices $A$ and $B$.

\subsection{A Climatology of Planetary Waves}

As has been pointed out in the preceding chapter, the ultralong and long planetary waves undergo considerable interannual variability in terms of their amplitudes, expressed as $A_{i m}$ or $\overline{A_{i d}}$, and their stationarity aspects, measured in terms of $A_{i m} / \overline{A_{i d}}$. The question arises: Can we define a seasonally varying state of planetary-wave behavior that 
describes a "normal" state for a given date of the year, from which "departures". can be recognized in the customary way?

We attempted to answer this question in the following way:

For each " $5^{\circ}$ latitude by $5^{\circ}$ longitude grid point north of $50^{\circ} \mathrm{N}$ a long-term mean value of the $500 \mathrm{mb}$ geopotential height was calculated for each calendar data (ignoring 29 February in leap years), using the data between 1945 and 1975. A more or less noisy mean seasonal trend curve could thus be obtained for each grid point. Examples are given in Fig. 2.4.1a. To remove some of the interdiurnal noise which is obvious-. ly caused by the passage of strong, but irregular synoptic systems, a 21-day running-mean filter was applied twice to this mean daily grid point data set (Figs. 2.4.1b and 2.4.1c). Even after this double smoothing procedure one does not end up with a simple harmonic curve representing a seasonal trend. Small irregularities remain indicating, perhaps, the presence of "singularities" in the course of the progression of seasonal weather patterns. Nevertheless, we assumed that the daily gridded values of the $500 \mathrm{mb}$ surface thus obtained represent the mean seasonal variability of that surface on a day-to-day basis. These values are stored on magnetic tape and can be obtained by other researchers upon request.

In Fig. 2.4.2 we have combined these daily mean grid point values into time sections as a function of geographic longitude and for different latitude circles. These time sections represent our interpretation of the mean seasonal variability of the $500 \mathrm{mb}$ surface. Since five-day mean values were used in Fig. 2.4.2, short-term noise has been eliminated.

An additional degree of smoothing is introduced by analyzing harmonically, along latitude circles, the daily mean gridded values, and by 


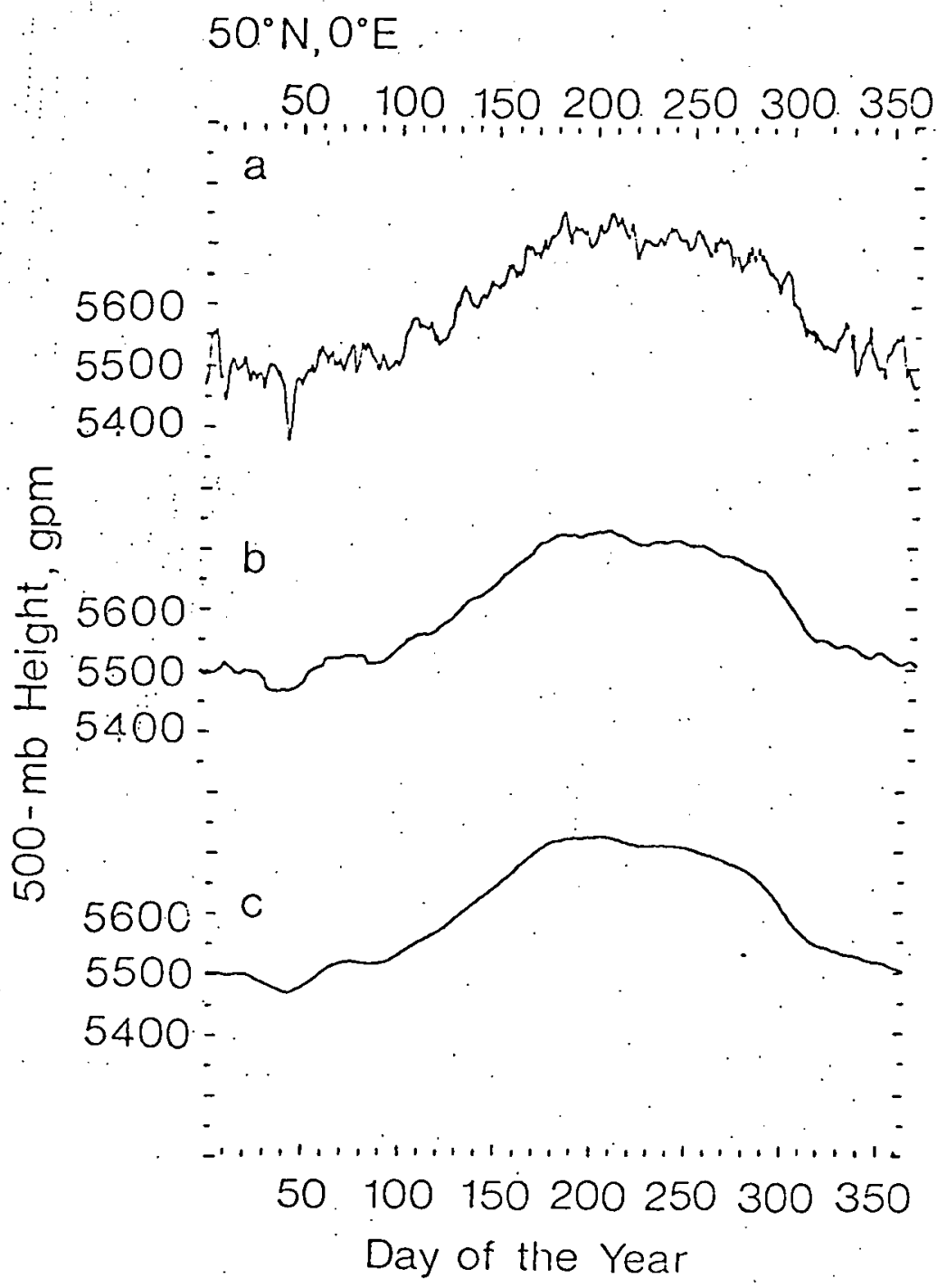

Fig. 2.4.1a,b,c Mean annual variation of $500-m b$ heights at grid point $50 \mathrm{~N}, 0^{\circ} \mathrm{E}$, using data from 1 January 1946 through 28 February 1979. (a) unsmoothed; (b) 21-day running-mean filter applied once; (c) same filter applied twice. 


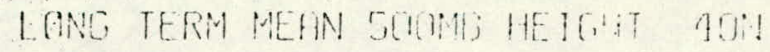

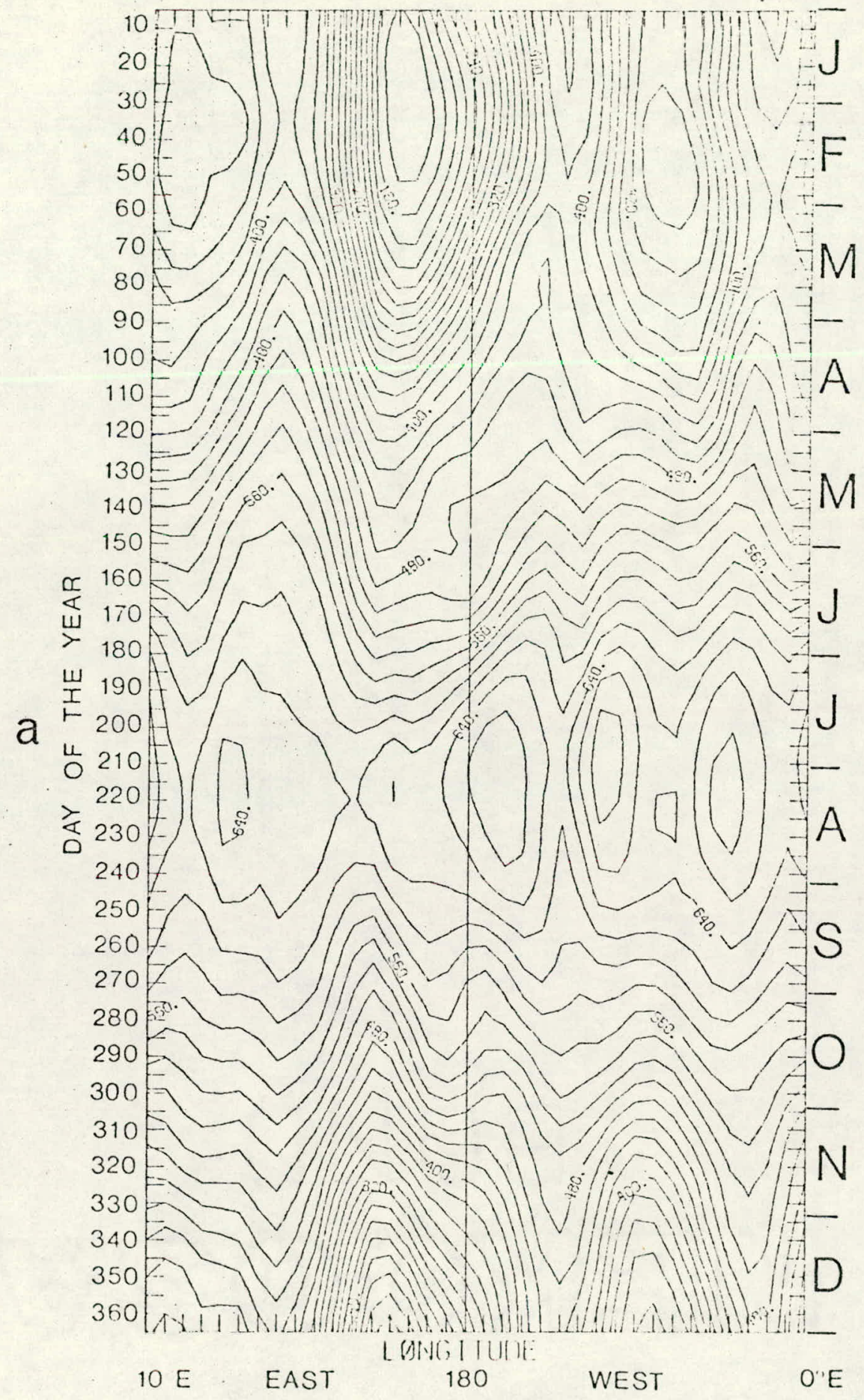

Fig. 2.4.2 Time-longitude sections at (a) $40^{\circ} \mathrm{N}$ and (b) $50^{\circ} \mathrm{N}$ of the 500-mb surface, averaged by dates for the period 1 January 1946 to 28 February 1979. Isopleths are drawn for every $20 \mathrm{gpm}$ as anomalies from $5200 \mathrm{~m}$. (Negative anomalies are indicated by dashed lines). Values analyzed are 5-day average heights. Dates given along the ordinate indicate the end of these 5-day periods. Marks along abscissa are for each $10^{\circ}$ longitude. 


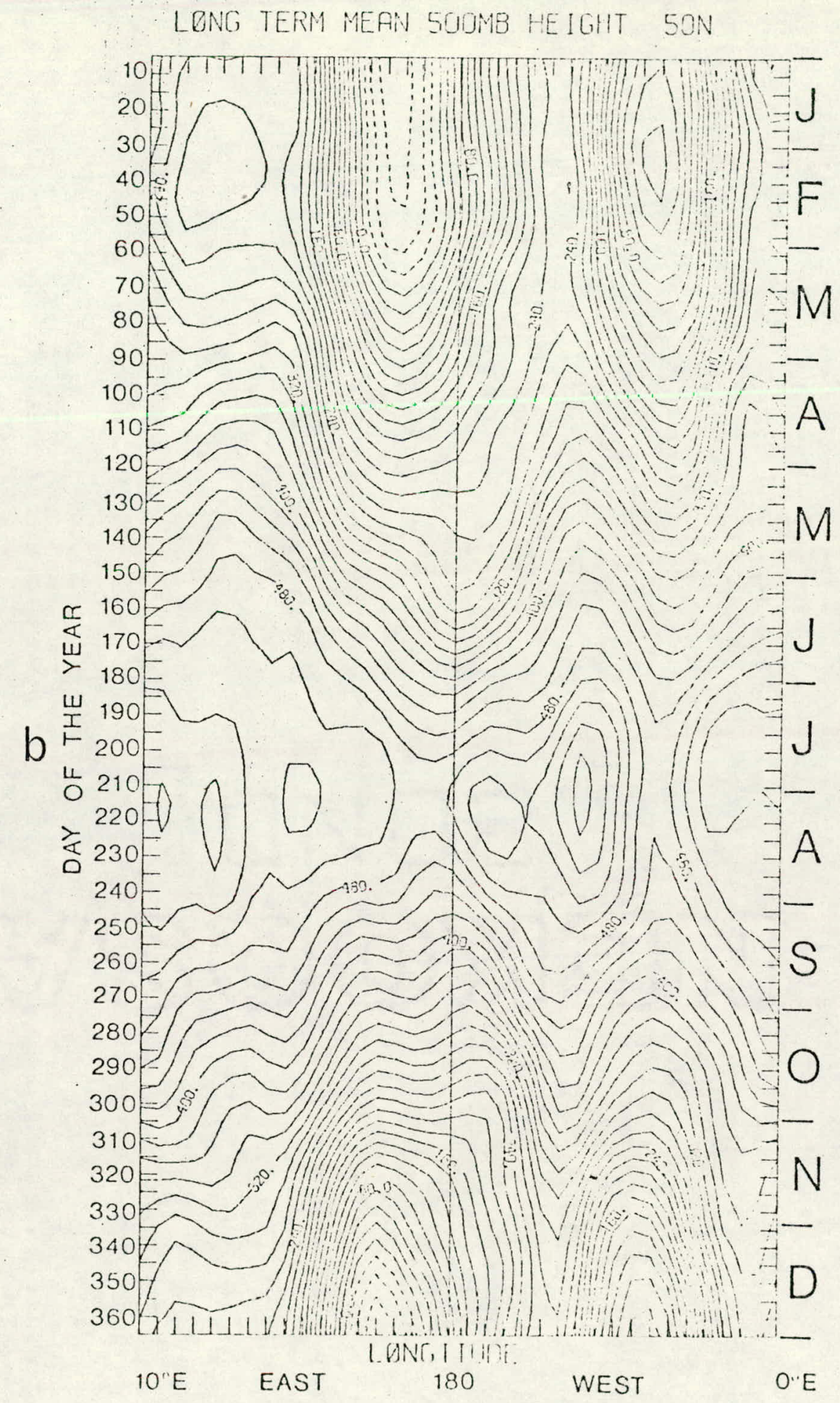

Fig. 2.4 .2 (continued) 


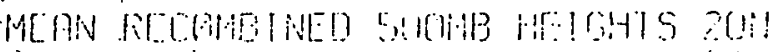

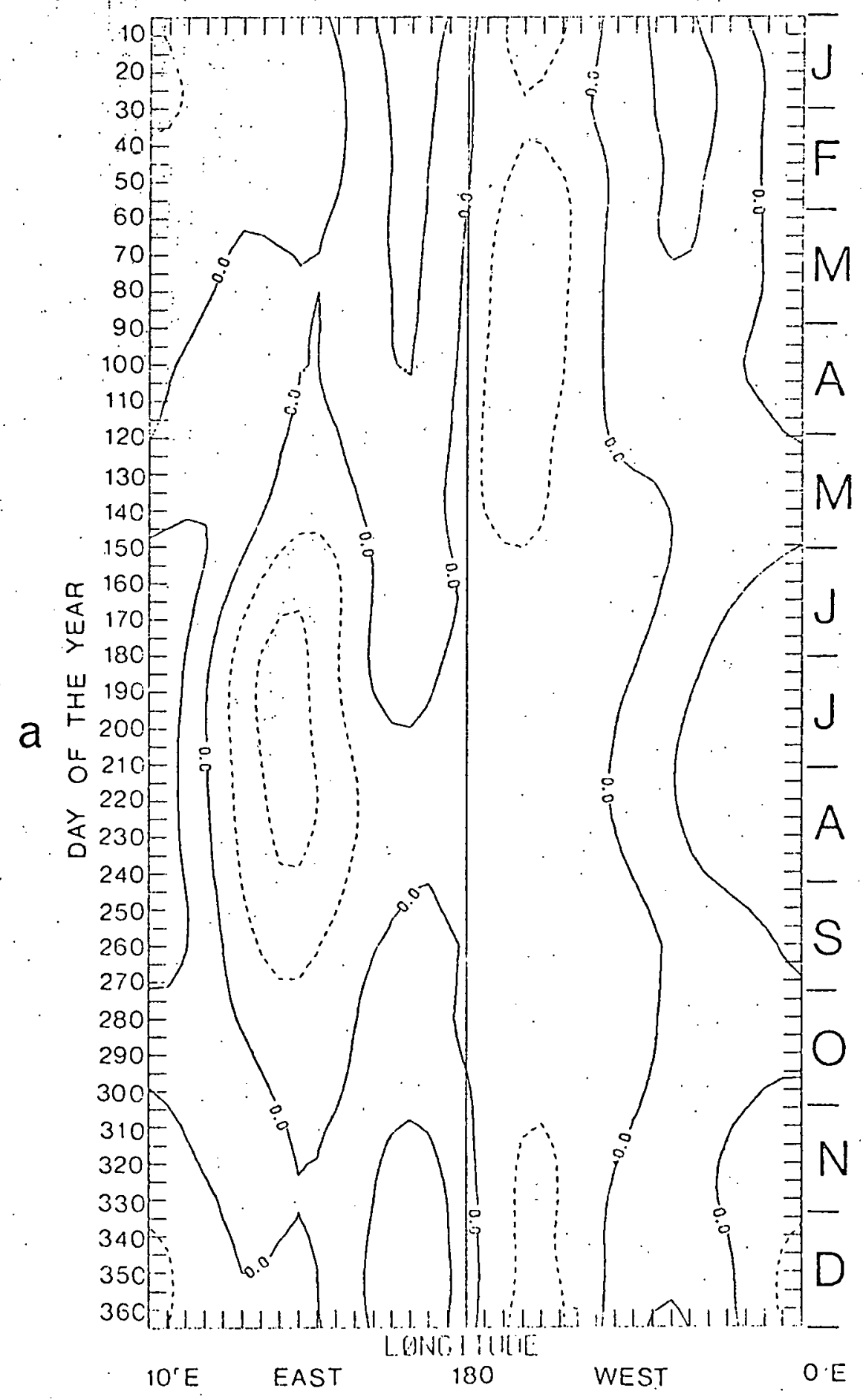

Fig. 2.4.3 Time-longitude sections at different latitudes (between $20^{\circ} \mathrm{N}$ and $70^{\circ} \mathrm{N}$ ) showing the contributions of planetary waves No. $1,2,3$ and 4 to the mean annual cycles of the 500-mb surface at these latitudes. Isopleths are drawn for every $20 \mathrm{gpm}$, negative values are indicated by dashed lines. Coordinates are the same as in Fig. 2.4.2. 
MEFN RECGMBINEO SUME HE LOS IL:

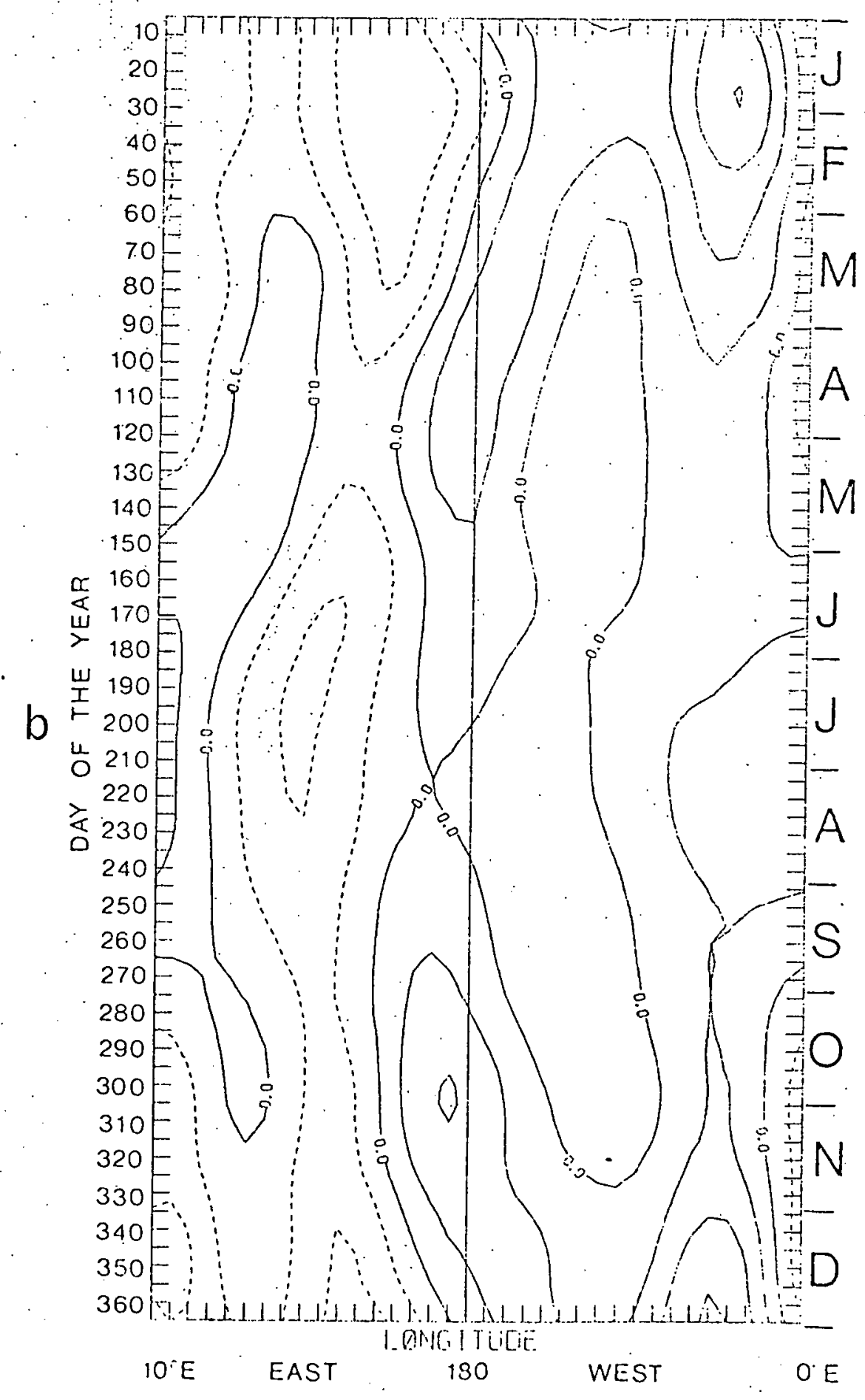

Fig. 2.4.3 (continued) 
MEFN RECOMBINEO 5OOHB HEICHTS AD::

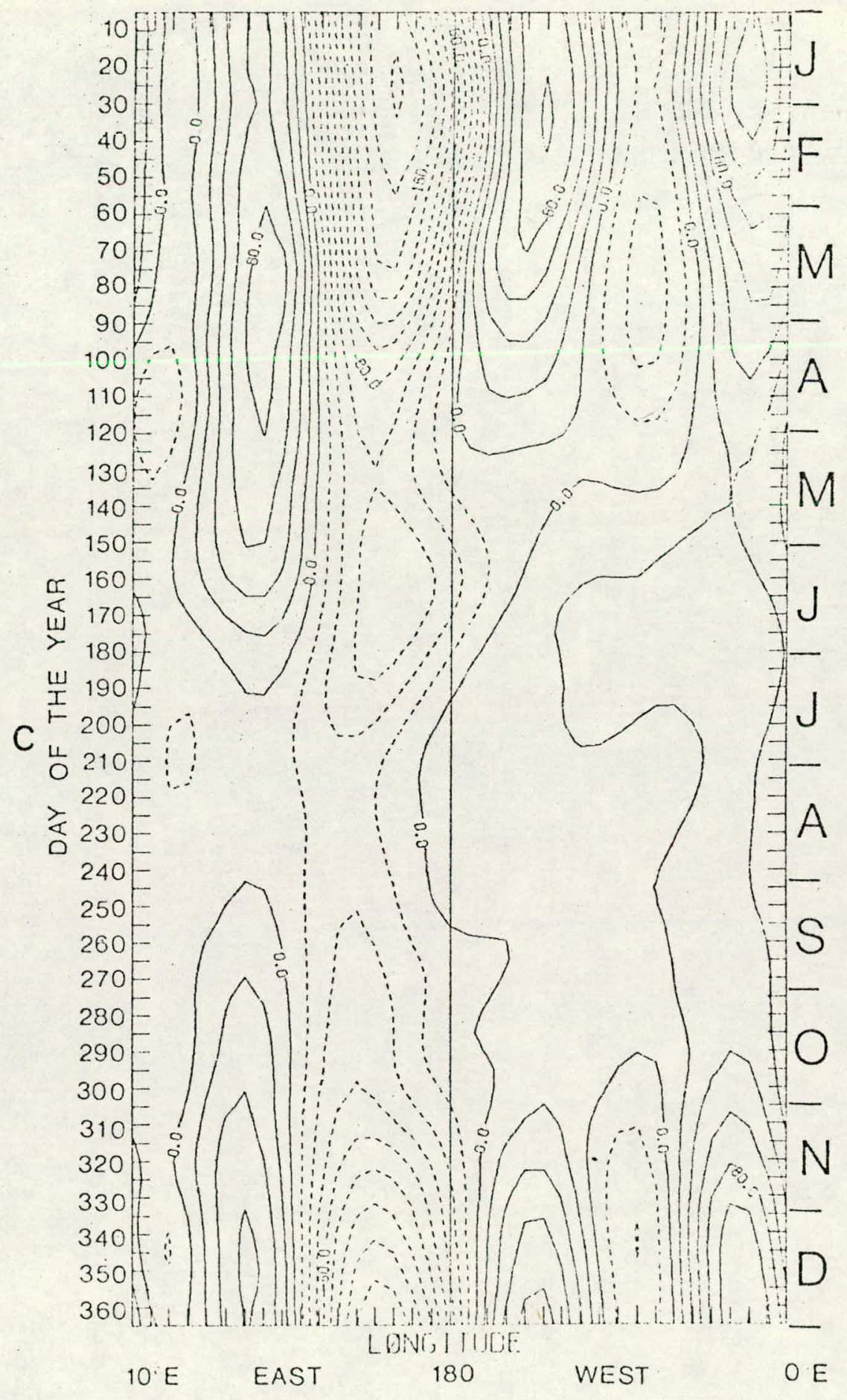

Fig. 2.4.3 (continued) 
MEAN RECOMBINEQ 5OOME HEIGHTS SON

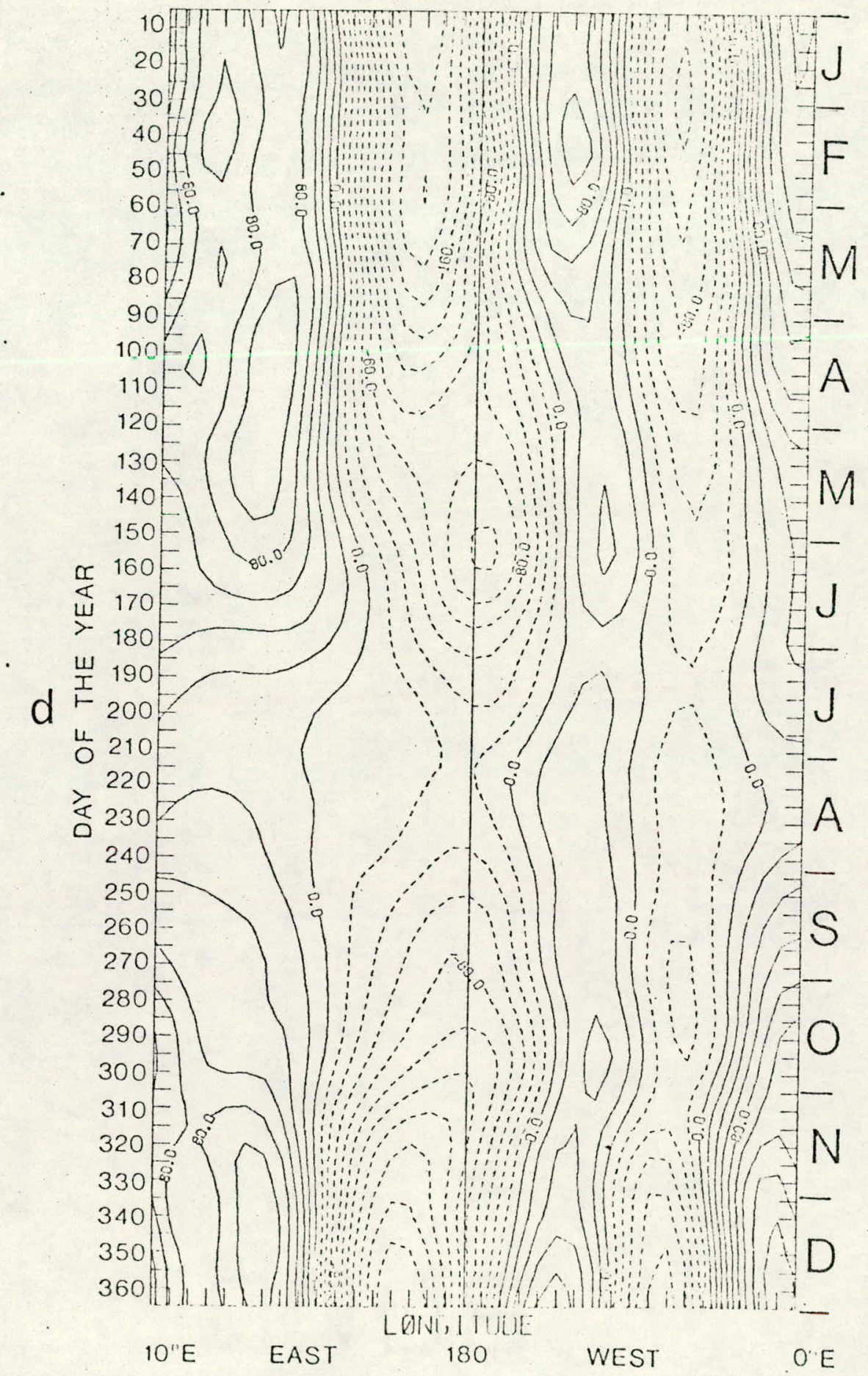

Fig. 2.4.3 (continued) 


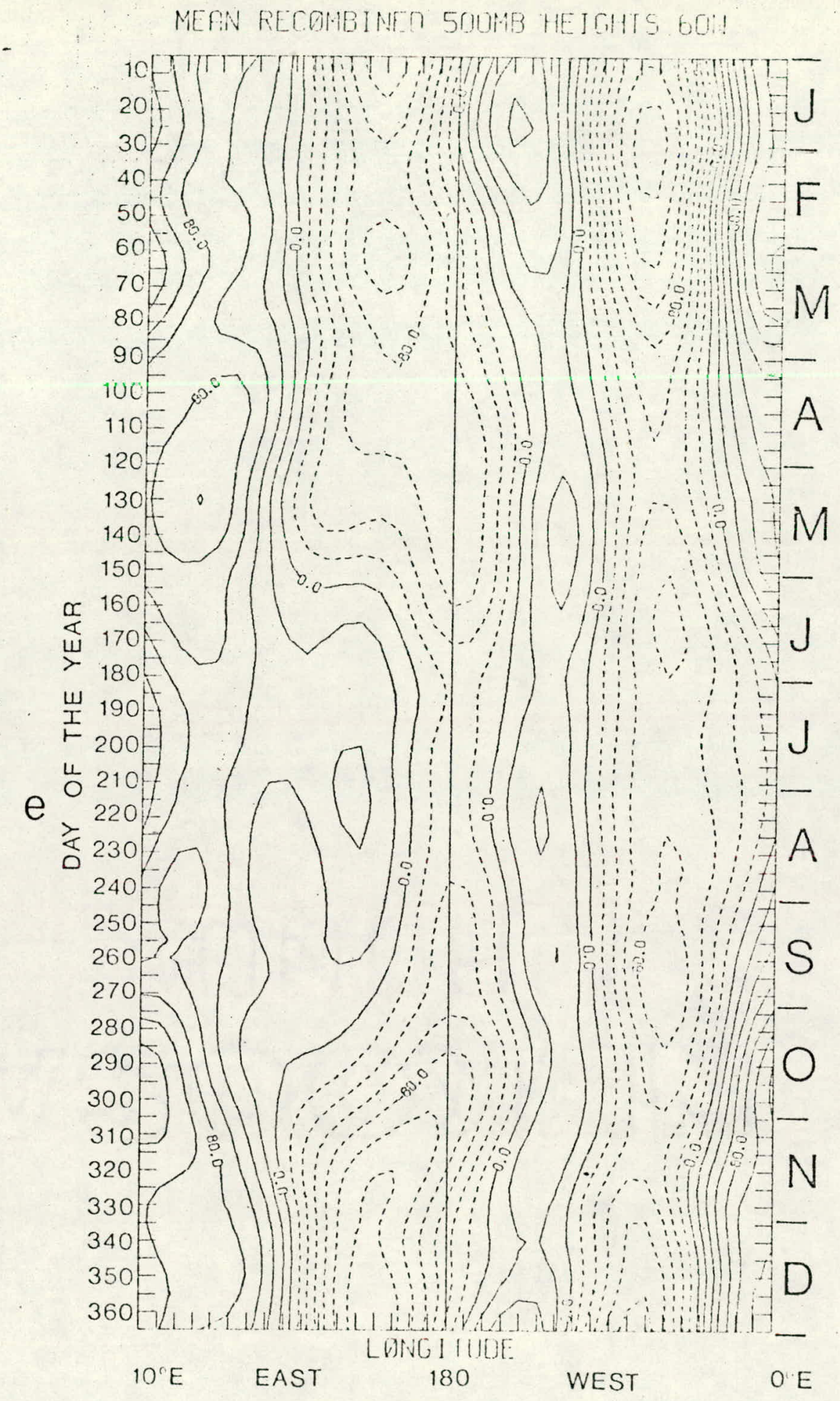

Fig. 2.4 .3 (continued) 
MEAN REGQHBINLC SUGHE HE IOHTS 7O?

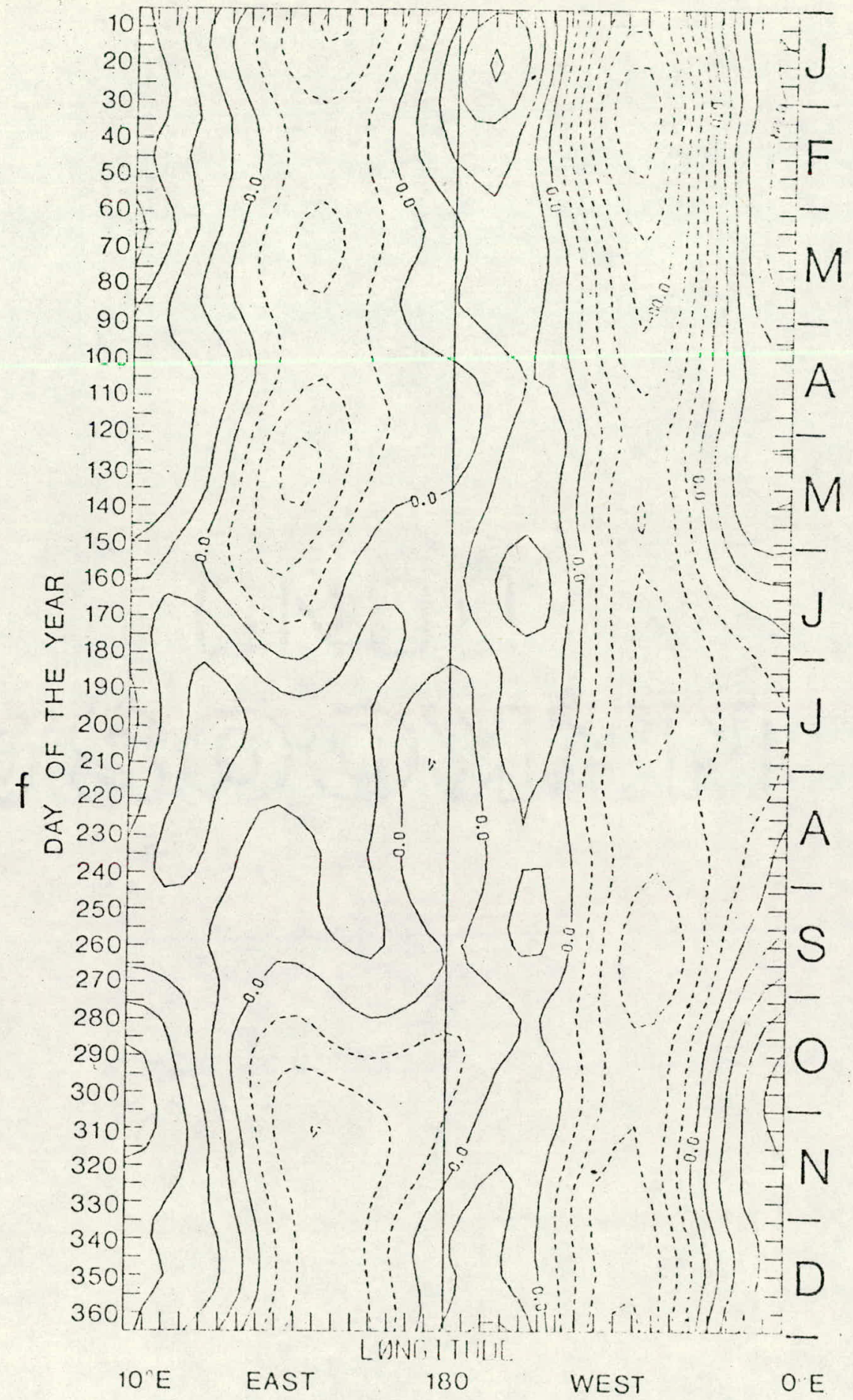

Fig. 2.4 .3 (continued) 
a

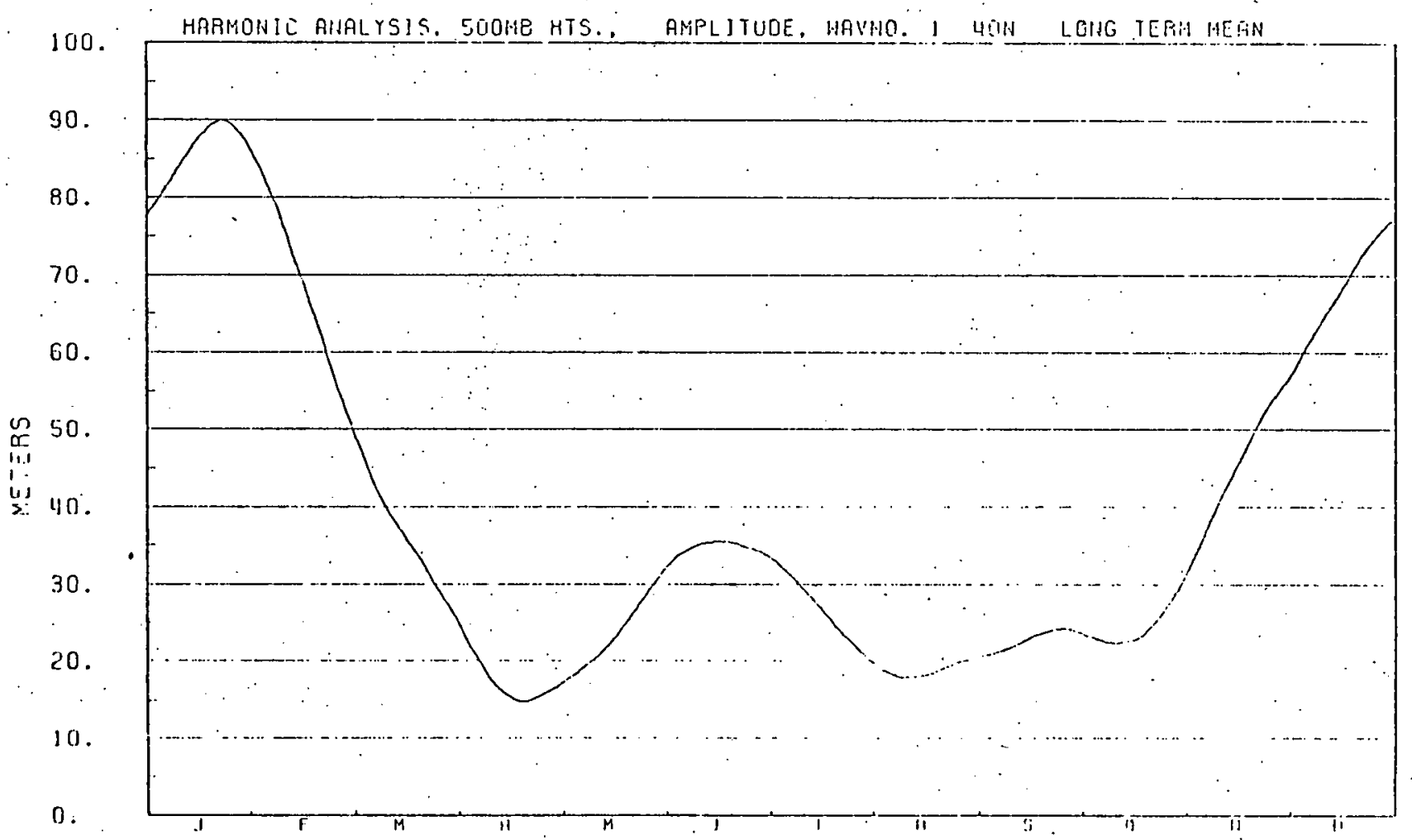

Fig. 2.4.4 Average amplitudes (in gpm) of planetary waves (wave numbers $1,2,3$, and 4) at $40^{\circ} \mathrm{N}$ as functions of the time of the year. 500 -mb heights averaged by date for the period 1 January 1946 to 28 February 1979 have been used as data base. 
b

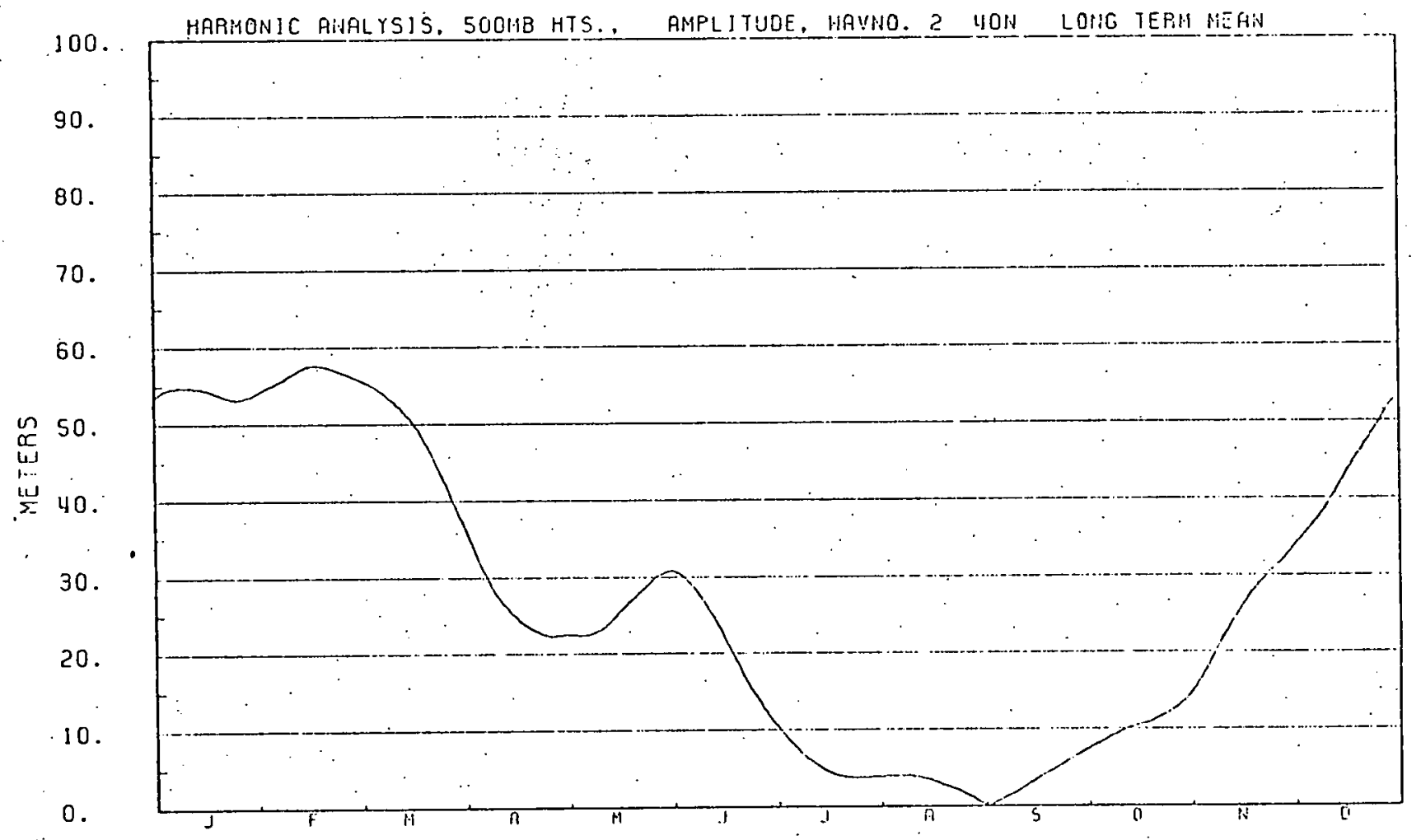

Fig. 2.4.4 (continued) 


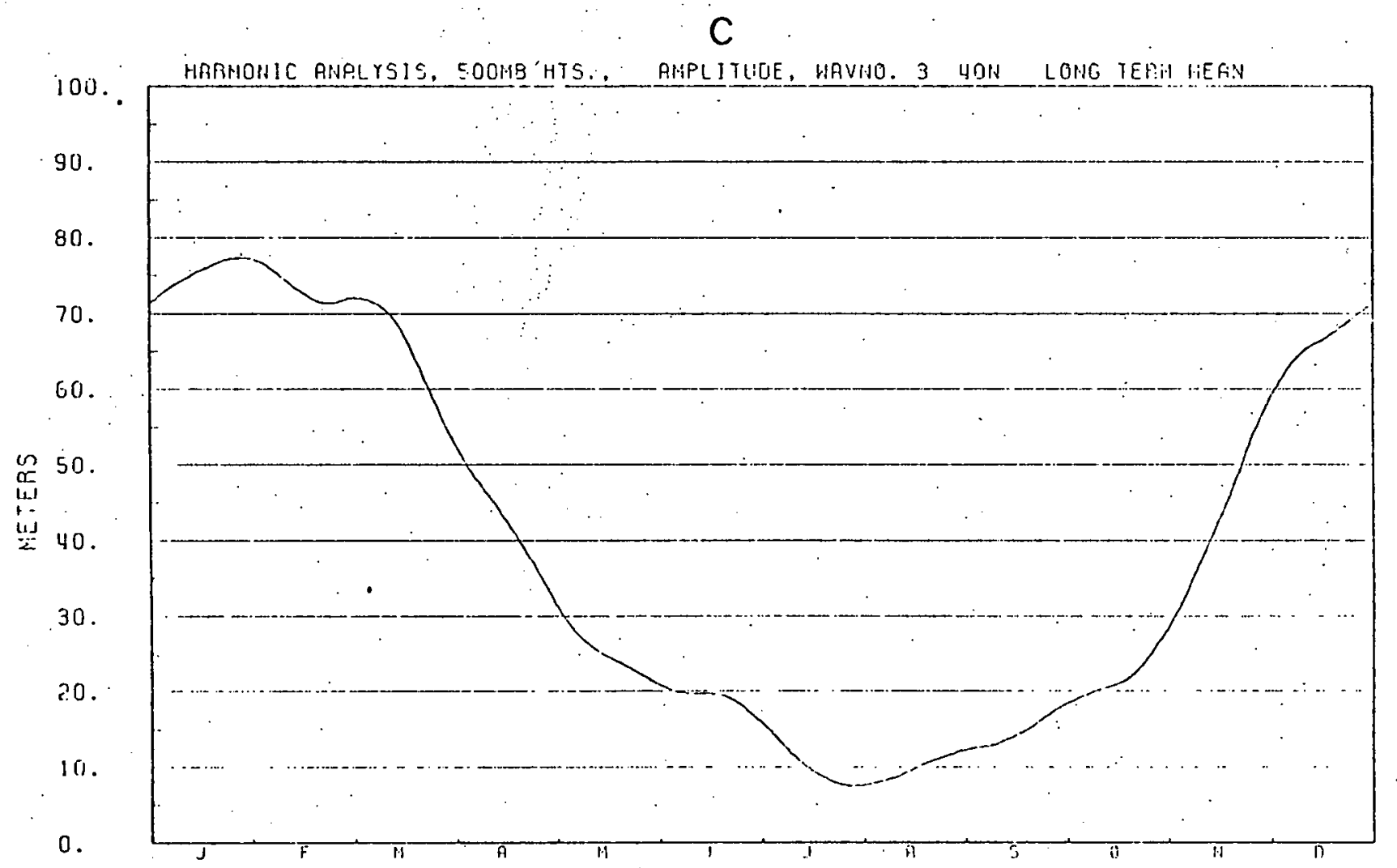

Fig. 2.4.4 (continued) 
d

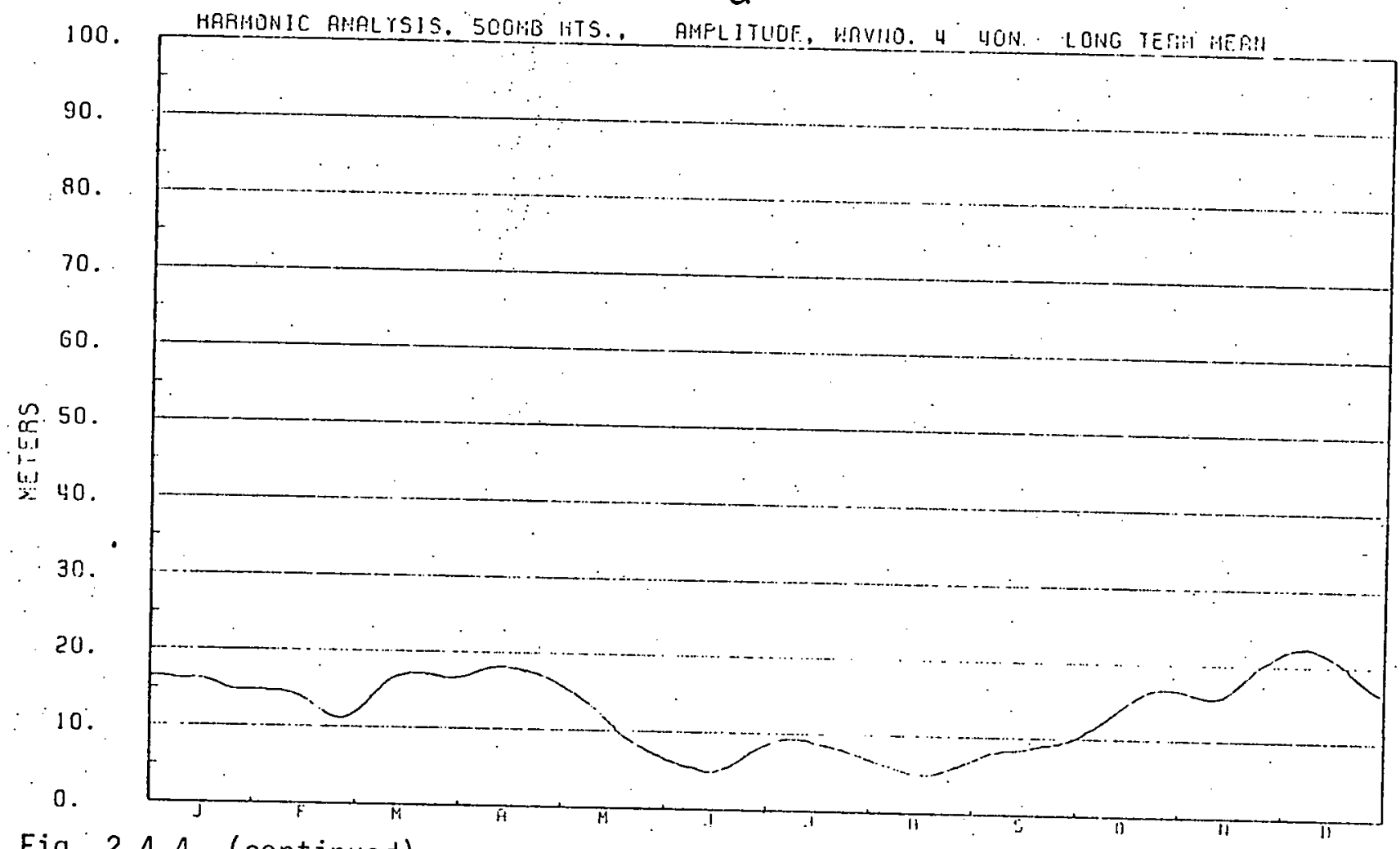

Fig. 2.4.4 (continued) 
a

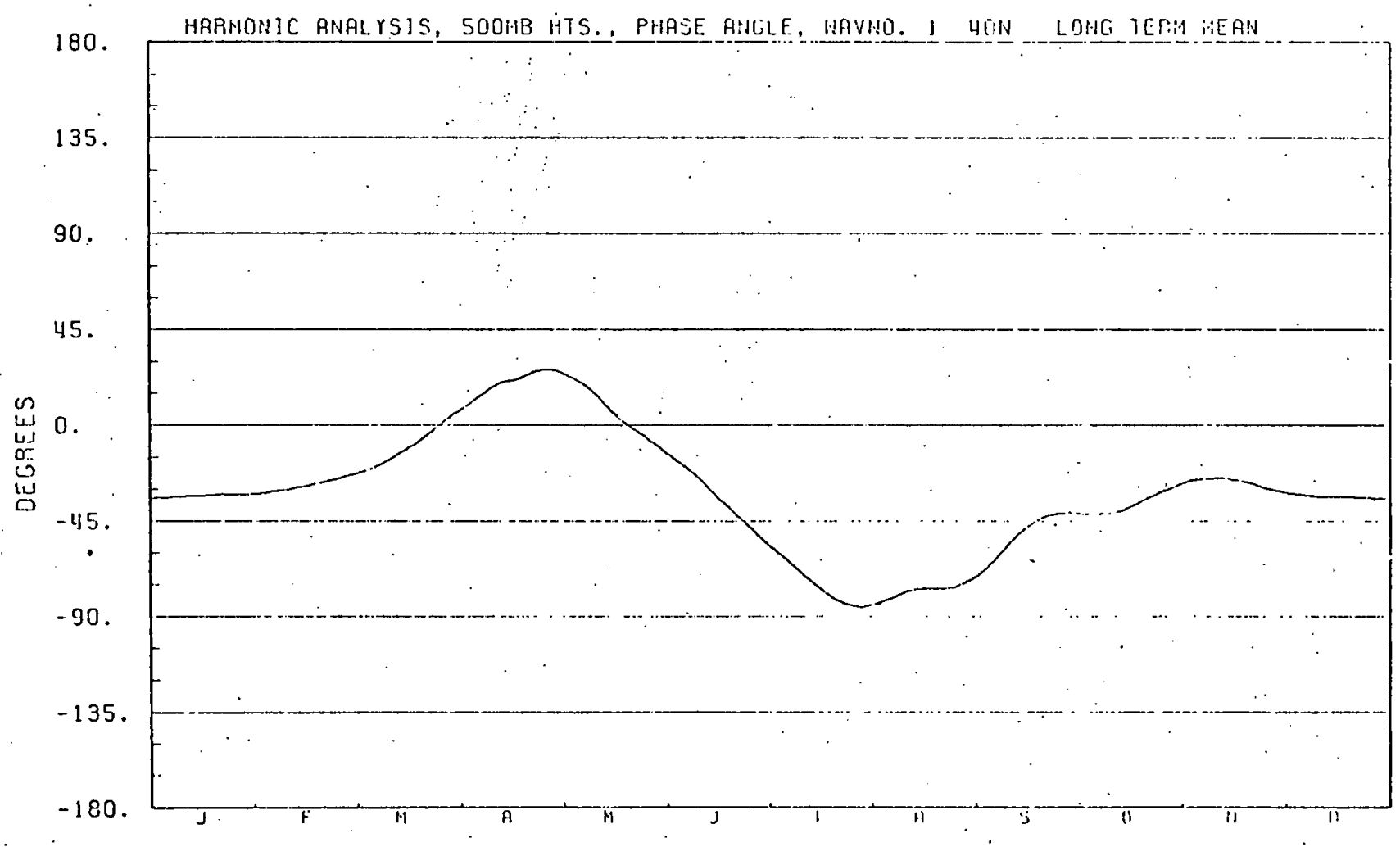

Fig. 2.4.5 Similar to Fig. 2.4.4, except showing the average phase angles of planetary waves. 


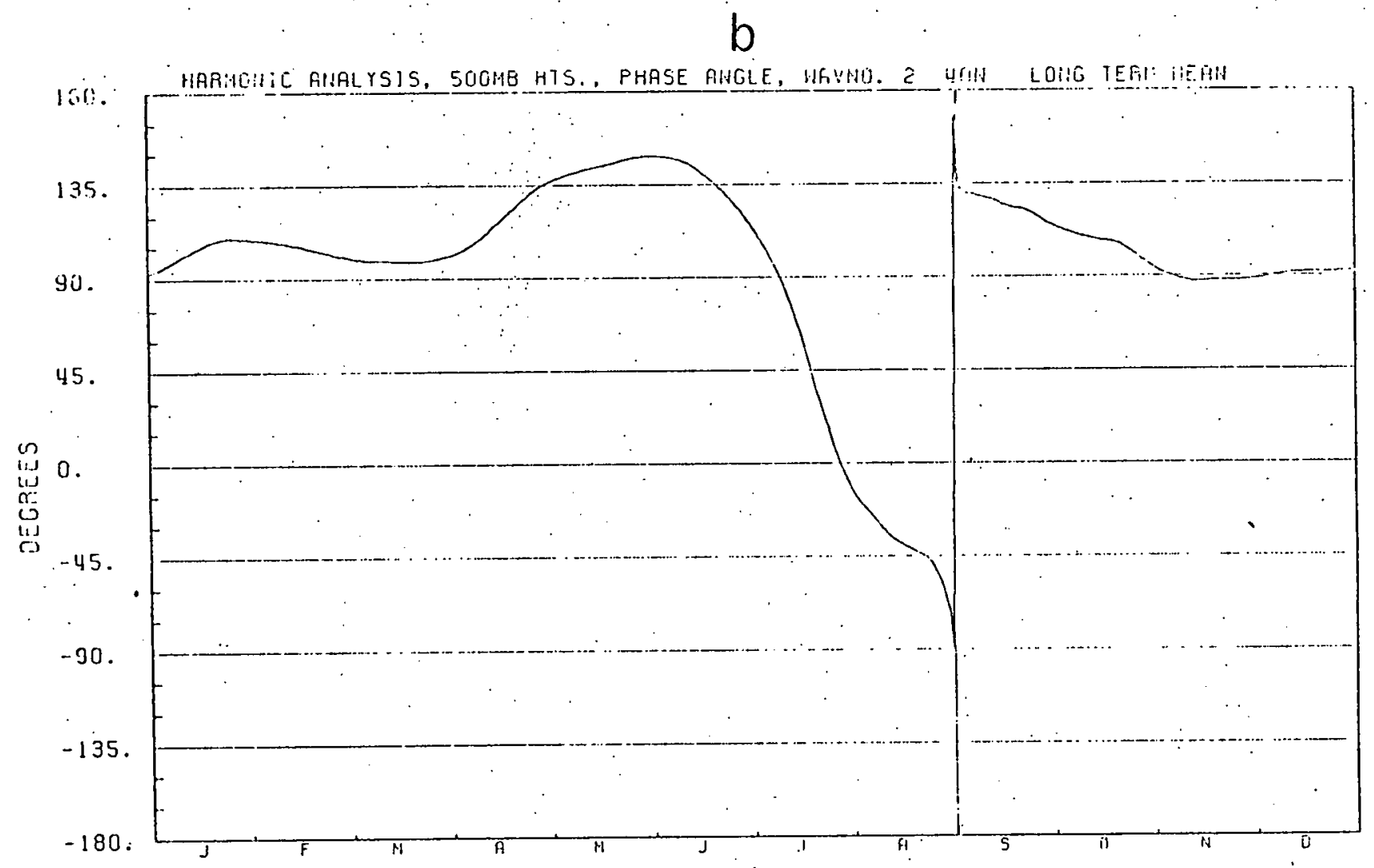

Fig. 2.4.5 (continued) 
C

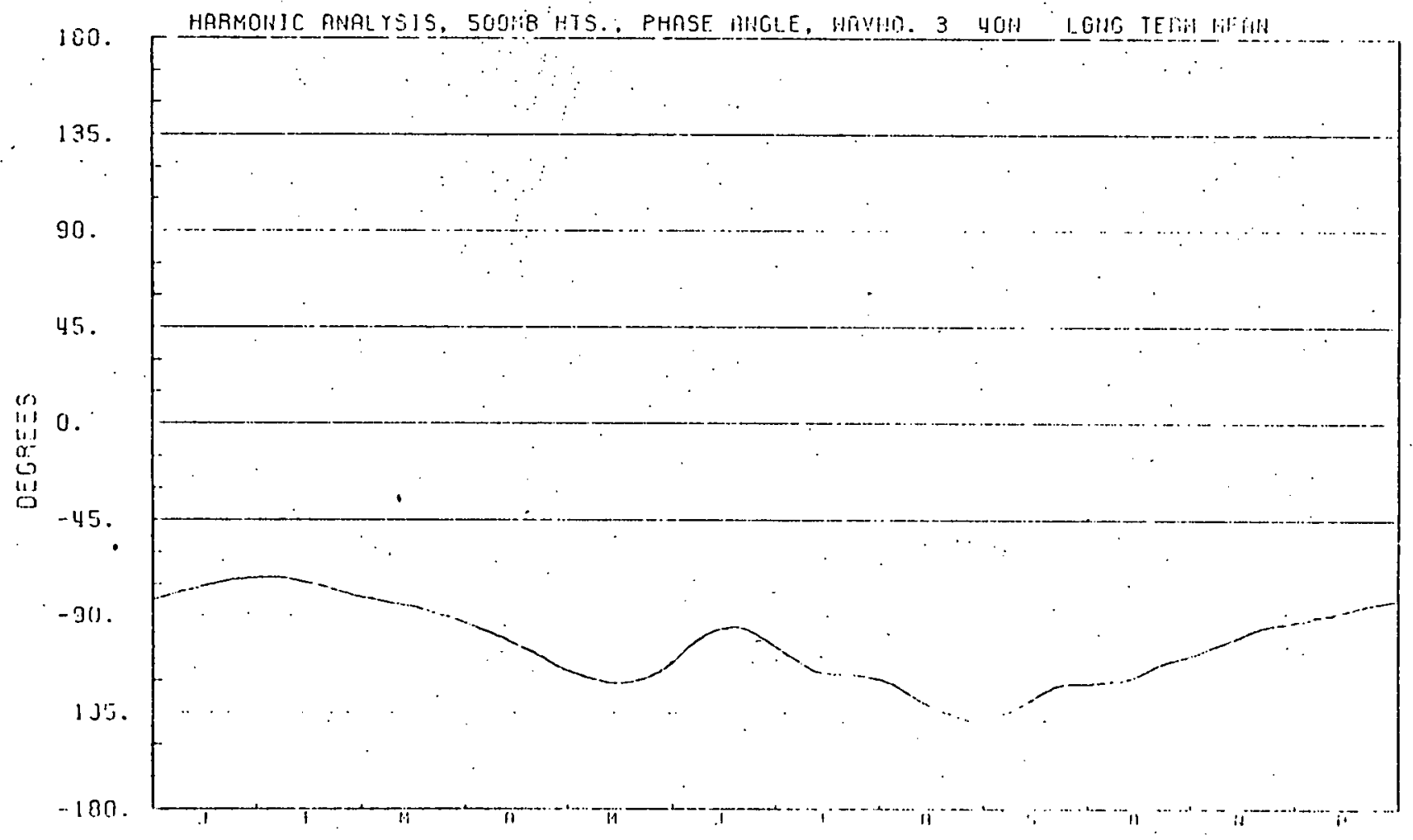

Fig. 2.4.5 (continued) 


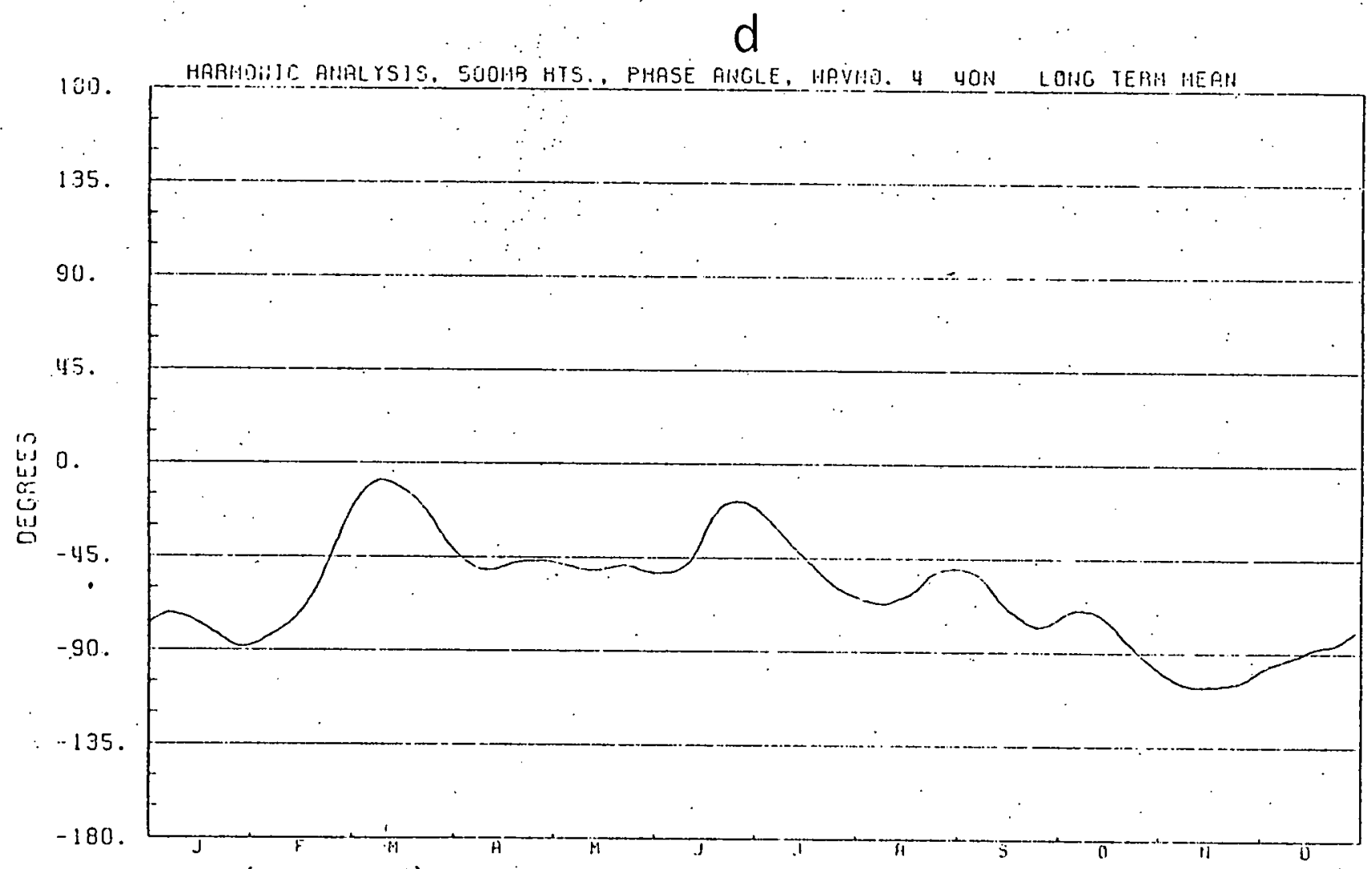

Fig. 2.4.5 (continued) 


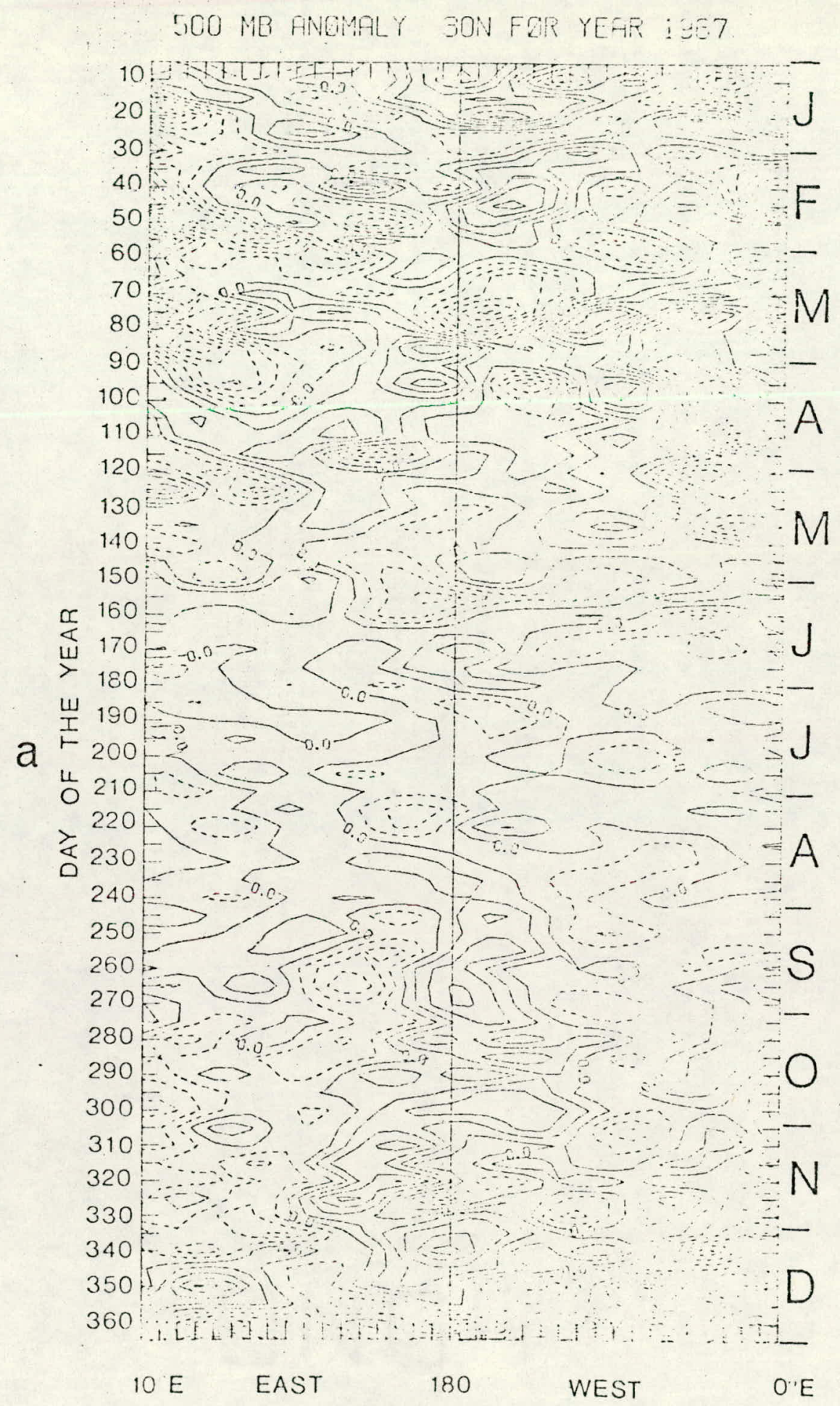

Fig. 2.4.6 Longitude-time sections of $500-\mathrm{mb}$ height anomalies at $30^{\circ} \mathrm{N}$ for years as indicated. Anomalies were computed by subtracting the smoothed long-term annual cycles of 500-mb heights at individual grid points from the daily values in the respective years, harmonically analyzing the residual, and re-compositing 5-day averages of the height field truncated for wave numbers $n>4$. Contours at $20 \mathrm{gpm}$ intervals, negative values indicated by dashed lines. 
500 MB ANBHAL Y 3ON FOR YEAR 1969

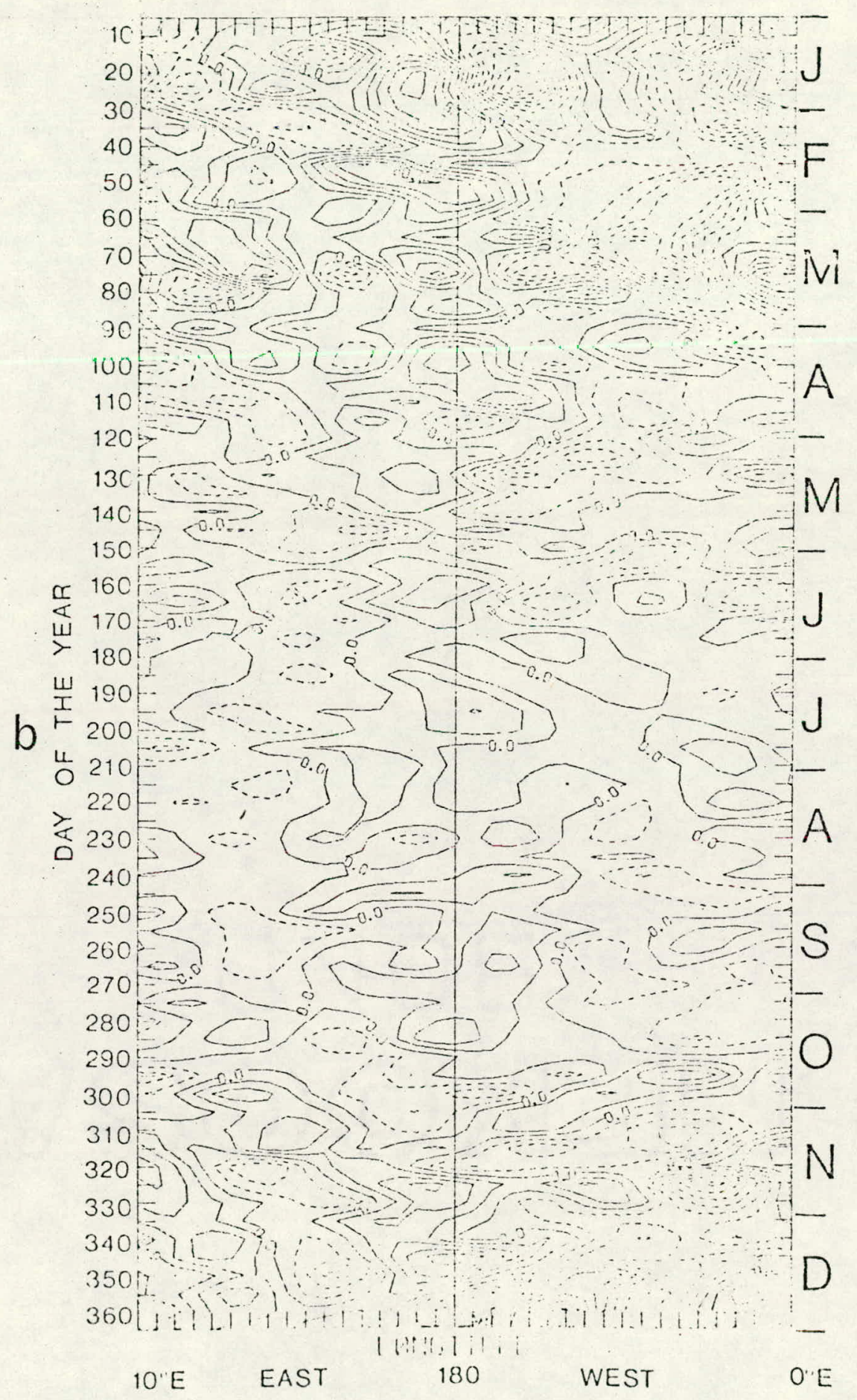

Fig. 2.4.6 (continued) 
500 MB ANEMALY SON FZR YEAR 1972

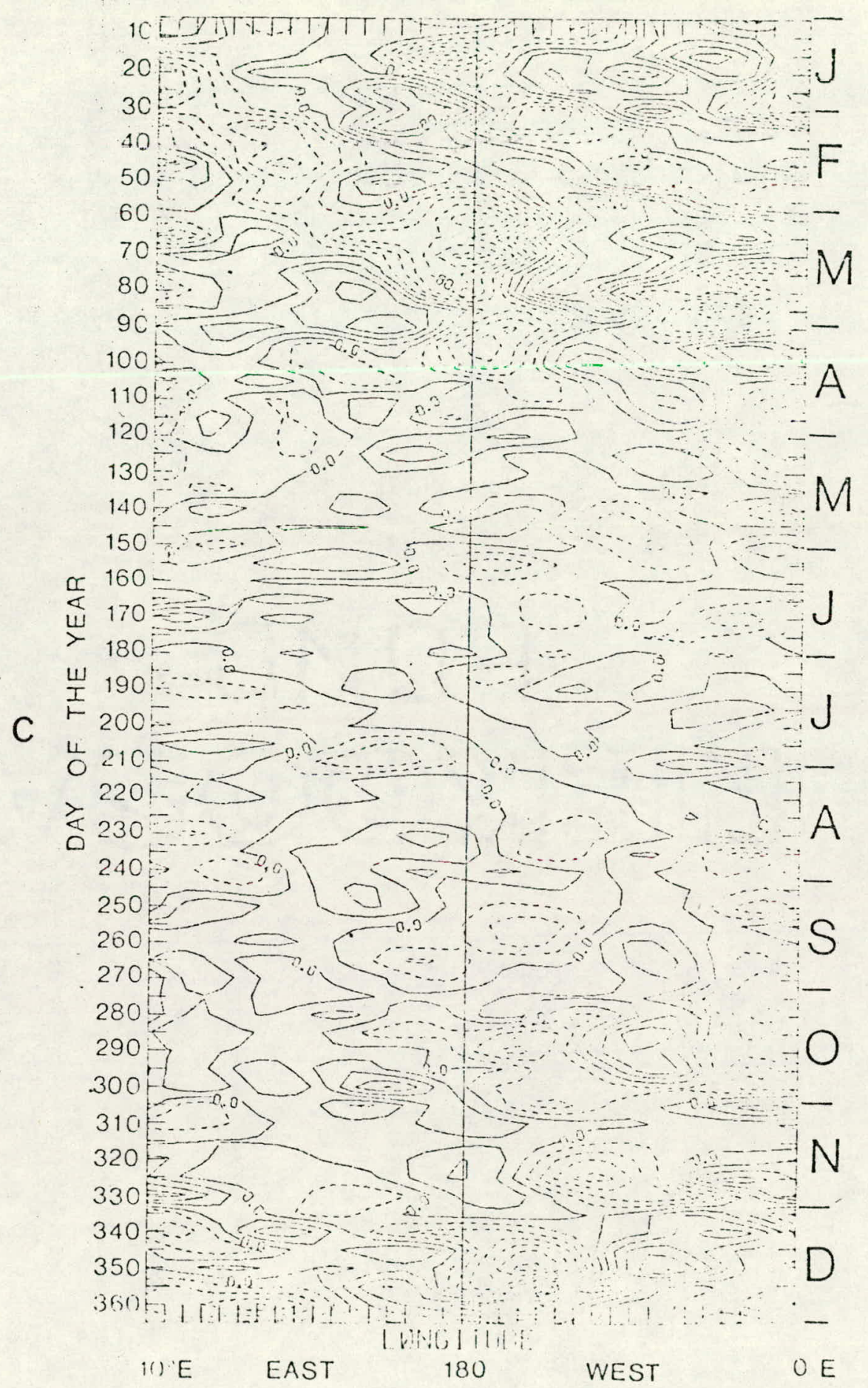

Fig. 2.4.6 (continued) 


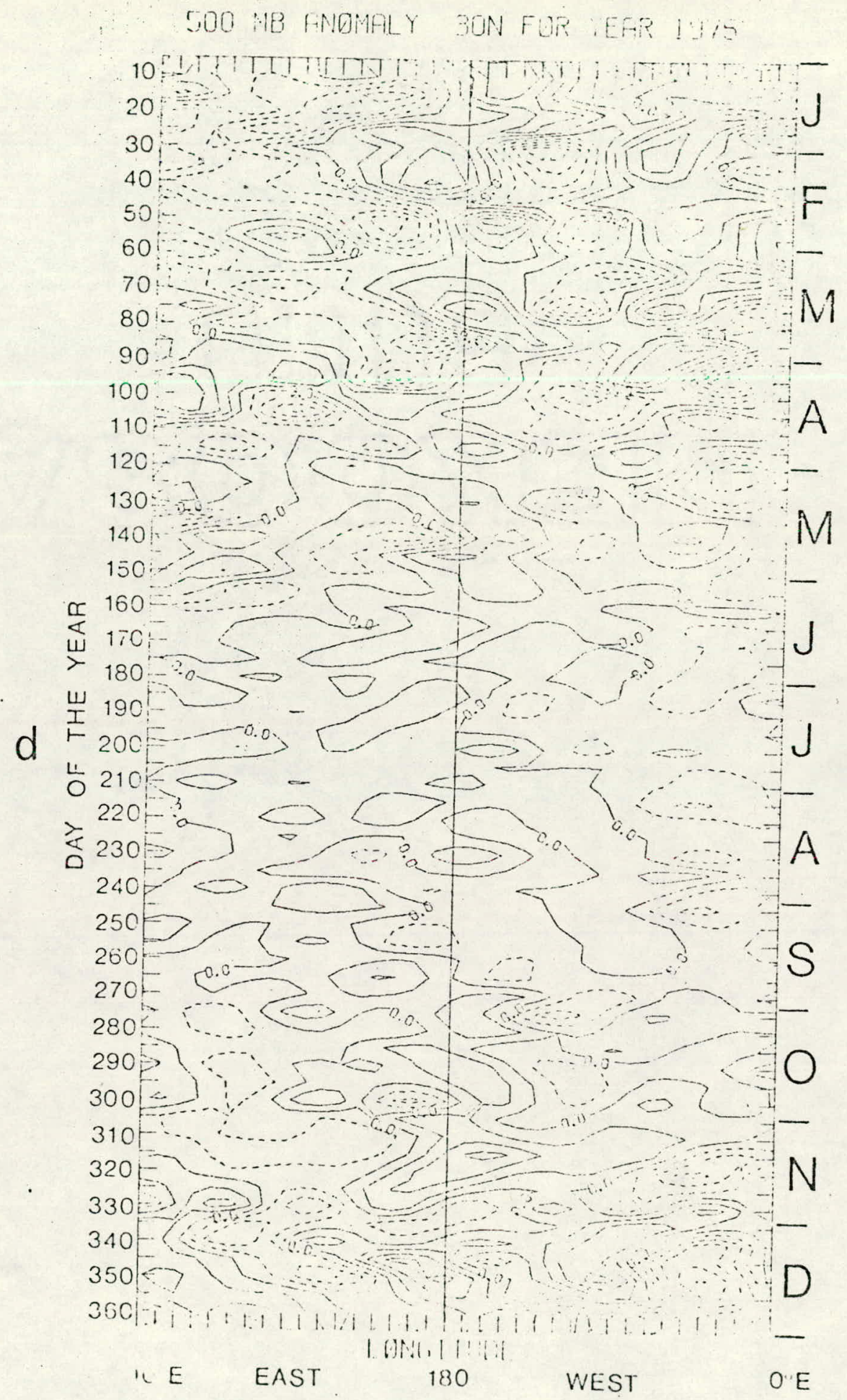

Fig. 2.4.6 (continued) 
truncating the harmonic expansion at a desired wave number. In Fig. 2.4.3 time sections of such a harmonic presentation, truncated after wave number $4 ;$ are shown. These time sectiuns can be construed as the mean seasonal variability of the ultralong and long planetary waves. This seasonal variability is also shown in Figs. 2.4.4 and 2.4.5 which gives the amplitudes and phase angles of the planetary waves, derived from the smoothed data set of Fig. 2.4.1c, as a function of time. These data, depicted in Fig. 2.4.4, constitute the mean seasonal behavior of planetary waves over a 30-year period. Such behavior will have to be emulated by those general circulation models which claim to have duplicated successfully the seasonal progression of atmospheric circulation systems.

A number of preliminary analysis steps have been carried out to date, using the climatological data set described above. As an example, Fig. 2.4 .6 shows time sections of anomalies of $500 \mathrm{mb}$ height patterns for various latitudes, truncated at wave number 4. The years 1967 and 1972 represent conditions with abnormally frequent typhoons, whereas the years 1969 and 1975 are characteristic of low typhoon frequencies. The anomaly patterns in Fig. 2.4.6 show that during summers with low typhoon frequencies rather persistent anticyclonic conditions (high-pressure anomalies) prevail in the centran North Pacific at subtropical latitudes. Years with many typhoons, on the other hand, are characterized by a less stable and persistent planetary long-wave pattern, allowing troughs to appear frequently at, and slightly west of, the date line. From this preliminary evidence it:appears that planetary wave activity strongly influences the tropical storm frequency in the North Pacific, a fact that has also been stressed elsewhere in recent publications by our 
group (Ding \& Reiter, 1980a and b). Analysis of conditions controlling Atlantic hurricane frequencies are presently underway. They begin to reveal a similar response to planetary wave patterns.

Using the gridded daily height anomalies of the $500 \mathrm{mb}$ surface between 1945 and 1975, we searched for long-term trends in these height values. Almost everywhere the $500 \mathrm{mb}$ surface shows a decreasing trend during that time interval. In some regions, e.g. over Siberia; these trends exceed $2 \mathrm{~m}$ per year. If we assume that the surface pressure of the northern hemisphere, integrated over the areal extent of the hemisphere, has not undergone any significant trend development by virtue of mass continuity, the trends of decreasing heights of the $500 \mathrm{mb}$ surface have to be interpreted as significant tropospheric cooling. As an order-of-magnitude guideline a tropospheric cooling by $1^{\circ} \mathrm{C}$ would lead to the reduction in height of the $500 \mathrm{mb}$ surface of approximately $20 \mathrm{~m}$ at average tropospheric temperatures.

\subsection{Causes and Effects of SST Anomalies}

As a prerequisite to a quantitative assessment of the distribution of oceanic heat sources and their variability we have to understand the role of the oceanic temperature distribution, especially in the mixed layer. It is well recognized that this temperature distribution -perhaps inadequately described by the relatively easily accessible SST anomalies --is. strongly influenced by the variance spectrum of the atmospheric parameters which control the surface heat budget of the ocean. The atmosphere, in turn, is susceptible to slow changes in the boundary conditions imposed by the SST patterns of the oceans. A rather complicated complex of feedback mechanisms evolves which has been investigated by many authors. Two recent studies can be listed as 
contributions from our group, attached to this report as Appendices $C$ and D. The wi 17 be issued as Environmental Research Papers No. 23 and No. 25.

The study by Middleton (1980) concentrates on the statistical treatment of the North Pacific SST anomalies at interannual time scales. The M.S. Thesis by Ciesielski (1980) deals with shorter-term interactions between the atmosphere and the oceanic mixed layer.

\subsection{Continental Heat Fluxes}

The assessment of the effects of continental heat sources and sinks on planetary-wave forcing will be one of the goals of our forthcoming grant period. We hope to be aided in these efforts by Mr. Gao Deng-yi, a young scientist from the People's Republic of China, who has worked for many years in the Xizang (Tibet) province on studies related to the main thrust of our proposed investigation.

A preliminary effort to assess the possibility of parameterizing heat fluxes from the ground to the atmosphere, using the Wangara data set from Australia, was started by R. Edson (1980) and has finally culminated in a M.S. Thesis (Appendix E).

\subsection{Data on Long-Term Climate Variability}

The P.I., was under instruction by the Department of Energy to explcre with colleagues in China the present state of research on historic climate records. Two major groups could be identified, doing such research. One is associated with. Professor Xie Yibing, Geophysical Institute of the University of Beijing. His research team has analyzed approximately 500 years of rainfall records, applying eigenvalue and spectral analysis approaches. The other group is attached to the 
Institute of Geography of the Academia Sinica in Beijing. It is using partly hïstorical records, and partly "proxy" data (such as tree-ring analyses) to study climate flucluations within the last couple of centuries. A more detailed report on these discussions will be forthcoming (Reiter, 1980b) as soon as transcripts of the extensive tape-recorded notes have been. made and edited. This report will also provide information on contact persons in China who are presently engaged in historical data collection.

3.. Studies on the Urban Mesoclimate

In the course of developing our community energy demand models, the requirement for monitoring the spatial variability of wind and temperature in the communities being studied has been an expensive and timeconsuming burden. This requirement was identified from our analysis of the energy demand for space heating of individual buildings in response to changing weather and in recognition of the well-known heat island phenomena of urban areas. In each community, data from our meteorological monitoring networks showed significant urban-rural gradients for near-surface temperatures and wind speeds (Reiter et al., 1978, 1979, 1980). Our analyses of these data confirmed that urban temperature distributions were sensitive to topography and wind direction, as well as wind speed. For at least two cases, a portion of the error in our predicted community energy demand was directly attributable to compromises in the development of the weather data used (Reiter etal., 1980).

Future applications of our energy demand models will require similar meteorological input data but cannot rely on costly monitoring programs for each new city. Hence, we are developing methods for projecting urban temperature and wind fields from a single set of local 
meteorological measurements plus distributions of surface cover, roughness and estimates of anthropogenic heat input. We will verify these climate modelling schemes using the data sets obtained from our Minneapolis, Minnesota and Greeley; Colorado monitoring programs.

As a first step we are developing surface source grids for both Minneapolis and Greeley. Parameters being determined for parh grid element include area-averaged indices of mean elevation, roughness, anthropogenic heat release and percent of surface covered with pavement, bare soil, high and low vegetation and roof tops. These grids will provide basic input information for our urban climate simulations.

Recent interest in urban climate, largely in association with air pollution studies, has provided several diverse approaches to simulating urban weather effects. In reviewing the literature we have sought methods that could be used to generate useful estimates of near-surface wind speed and temperature distributions with a minimum of input data, computational complexity and developmental effort.

An obvious step to reduce model complexity is to simulate the wind and temperature fields separately, thereby utilizing steady state methods for each parameter and avoiding many continuity and closure requirements.

We are studying the usefulness of a simple power law relation, Eq. 3.1, for simulating urban wind speeds.

$$
U=U_{r}\left(z_{r}\right)^{\alpha}
$$

Empirical constants for use with this equation were developed in a recent wind energy research program (Spera and Richards, 1978). The terms $U_{r}$ and $Z_{r}$ designate the wind speed and elevation above the 
surface, respectively, for a reference wind sensor. The exponent $\alpha$ is determined from Eq. 3.2.

$$
\alpha=\alpha_{0}\left(1-\log u_{r} / \log U_{0}\right)
$$

where $\alpha_{0}$ is an empirical roughness exponent and $U_{0}$ is an empirical homogeneous wind speed (approximately $67 \mathrm{~m} / \mathrm{s}$ ). Cursory tests of Eq. 3.1 for relating average Minneapolis airport (10 meter tower) wind speeds to urban area winds (measured at 3 to 7 meter elevations) have been successful for moderate to strong winds at most locations. The comparatively low sensitivity of energy demand for space heating to wind speed (Reiter, 1980) further suggests that the above relation will suffice for adjusting surface wind speeds to the various roughness situations encountered in most urban areas.

We are presently testing the applicability of an advective thermodynamic boundary layer model for simulating urban temperature fields. This model, based on original'work by Summers, 1965, has been adapted and modified by Leahey and Friend, 1971; Lahey, 1975; Bowling, 1978 and Henderson-Sellers, 1980.

Following Leahey and Friend (1971), the computational form of the model is given by Eq. 3.3.

$$
h^{2}(x)=\frac{2}{\rho C_{p} \| \beta} \int_{X_{0}}^{x} Q_{c} d x
$$

Independent variables in this equation include air density $(\rho)$ which is assumed constant, specific heat of air $\left(C_{p}\right)$, mean wind speed $(U)$, also assumed constant, and $\beta$, the difference between the dry adiabatic lapse rate $(\Gamma)$ and the lapse rate $(\gamma)$ in the stable rural air being advected into the city (i.e. $\beta=\Gamma-\gamma$ ). $Q_{c}$ represents the rate of sensible heat 
input at the base of the mixed layer over the city surface. This model crudely simulates the modification of a surface-based layer of stable air as it is advected from a rural source area into an urban area. Sensible heat from space heating and other urban sources is assumed to mix adiabaticaliy into the bottom of the stable layer and form a surface-based adiabatic mixing layer of height $h$. The general validity of the assumption of adiabatic mixing of heat from urban anthropogenic sources has been verified by DeMarias, 1961; Clarke, 1969; Baker et al., 1969, and in our analyses of temperature data taken from a 150-meter tower located in the center of the Minneapolis-st. Paul metropolitan area.

Solving for h along a series of parallel linear trajectories (wind direction is also assumed constant) over a grid of heat source elements representing a city, yields a two-dimensional field of mixing height values. Surface temperature values are then computed using Eq. 3.4 .

$$
T_{U}(X)=T_{R}+\beta h(x)
$$

where $T_{u}$ and $T_{R}$ are city and rural surface temperature values, respectively. It is assumed that there are no surface temperature gradients in the rural air upwind of the city.

Since this model was developed for investigating wintertime (i.e. heating season) urban heat island effects, the basic formulation and assumptions tend to preclude its use when the upwind temperature profile is neutral or superadiabatic (that is $\dot{\gamma} \geq \Gamma$ ). However, it is during such periods (usually high winds and clouds or very bright winter sunshine) that urban heat island development is ordinarily minimal and its simulation of least significance. Also, by stipulating that $y$ always 
remain at least slightly stable, some resịdual heat island effects will be retained in the model.

It is apparent that importanl aspects of this modelling approach are the estimation of $y$ and the accomnodation of urban inversions under calm and clear conditions. At present we are studying a method presented by Carlson and Boland (1978) by which the thickness of a developing surtace-based inversion is computed from the time integral of friction velocity. The lapse rate (assumed constant) through this stable layer is then computed with a second relation involving estimates for the surface energy balance. We anticipate that this same method or a similar adaptation will be applicable for estimating $\gamma$ as well as for simulating inversions within communities where irregular topography results in significantly different surface temperatures along hillsides and in valleys.

During the remainder of the present contract period we will perform more exhaustive analyses of our urban meteorological data sets and adapt and modify the wind and temperature models to best reproduce the results of these analyses. We, anticipate that most developmental work will focus on our Minneapolis data because of the availability of wind and temperature data from the 150-meter tower. However, as outlined in our last proposal, a major effort involving Greeley data will look at the influence of heavy snow cover on mitigating urban-rural climate differences.

4. Energy Demand Modelling

\subsection{Introduction}

Our work during the present contract period includes several neiv energy demand studies and field data collection efforts plus a number of 
innovations and refinements in our modelling procedures. Progress in each of these areas is briefly summarized.

\subsection{New Modelling Studies}

Data collection programs have been undertaken to obtain basic information needed for several specific energy modelling exercises to be pursued during the remainder of the contract perind. In a reinvestigd" tion of space heating demand for energy in Greeley, Colorado, we are attempting to document the effectiveness of the Federally mandated $65^{\circ}$ thermostat setting for public buildings during the 1979-80 heating season. Also, data collected for the Greeley program will be used as a first test of our hybrid, reference-physical modelling procedures.

A summertime data program, currently underway, involves the weather dependent energy consumption for air conditioning in five large office buildings. These cooling season data will be used to develnp prototype building modules for eventual use in a community cooling demand model.

One additional program involves identifying and collecting meteorological, gas consumption and building census information for a regional space heating demand model.

\subsubsection{Reinvestigation of the Space Heating Energy Demand in Greeley, Colorado}

Our primary objective in conducting another analysis of energy consumption for space heating in Greeley was to assess the effectiveness of President Carter's order for conservation through mandatory $65^{\circ} \mathrm{F}$ thermostat settings in public buildings. Our physical model appears to be sufficiently accurate to make this determination and the results of 
this study will be of value in the design and evaluation of future mandatory programs of this sort.

Physical and stalistical reference models of energy demand for space heating in Greeley were described in our prior reports (Reiter et al., 1976, 1978, 1979, 1980). In these studies a detailed building census for Greeley was developed. Consequently, the work required for the current program was limited to updating the building census, obtaining daily gas consumption data, and gathering detailed meteorological data for the ci.ty.

The Greeley building census contains physical data for all buildings in the city. Hence, the location, age, type of construction, square footage and use (i.e. office, residential, retail, etc.) for all new structures (built since March 1977) had to be determined for the census update. A listing obtained from the Building Inspector's office contained all the required new information except for square footage which had to be extracted piecemeal from the inspector's files. This listing included approximately 1,400 new buildings or, roughly, a 10 percent increase in the total number of buildings in Greeley since 1977. This remarkable rate of growth is consistent with local population increases. Nearly 90 percent of the new buildings were single-family dwellings. Figure 4.2.1 summarizes the spatial distribution of new construction. in Greeley for both residential and nonresidential buildings. Interviews with local utility officials confirmed that nearly 100 percent of these new buildings are heated by gas.

Weather data for the Greeley area were obtained from a network of six weather stations operating in the same locations as in our previous Greeley programs. Mcteorological monitoring began on December 1, 1979 


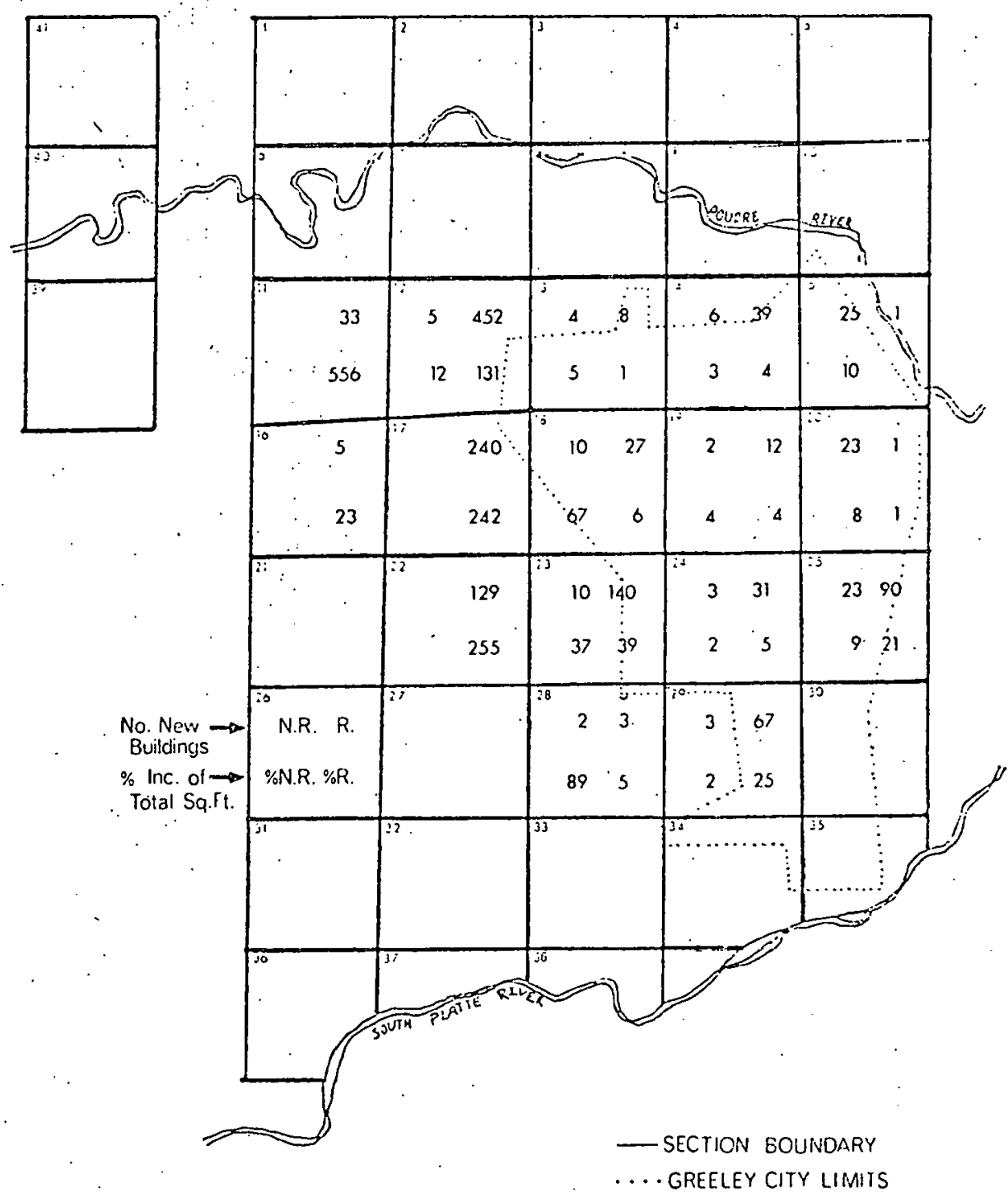

'Fig. 4.2.1 Sumiary of Greeley building census update from March 1977 to October 1979. Sixteen of the 41 Greeley sections show significant development. Data represented for each section include the number of new nonresidential (NR) and residential (R) buildings and the percent increase of total square footage for each of two classes of buildings. 
and ended prematurely on February 20, 1980 when uncertain funding forced us to terminate the observers and to put our entire program into a phase-out mode. Nevertheless, a good record of temperature was obtained at all six stations and excellent wind data were gathered for three of the five stations where wind was monitored. Solar radiation data were provided by the University of Northern Colorado. Data-chart reduction and keypunching has recently been. completed for all meteorological parameters and, after patching in missing data and performing a few quality tests, the records will be available for energy consumption modelling. During the remainder of the present contract period these meteorological data will also be extensively analyzed and compared with data from our past Greeley studies. The recent (1979-80) cold and snowy winter in Greeley is in marked contrast to the 1976-77 winter which was very warm and dry. We anticipate that comparative analyses of these data sets will be of value in the validation of our urban climate model.

The final portion, of the 1979-80 Greeley data program was the collection of natural gas consumption data. Daily aggregated. consumption data for the city, provided by the Greeley Gas Company, were adjusted by removing the daily consumption of two industrial customers whose processes consumed large quantities of gas. Gas company officials confirmed that during the winter gas supplies were ample and no supply curtailments had been made to interruptable customers. Daily gas consumption was also recorded for several large buildings that had been used for module validations during our previous Greeley studies. These data will be used as an additional check for deviations in consumption patterns. 
During the remainder of the contract period we will evaluate the energy savings realized in Greeley by the national $65^{\circ} \mathrm{F}$ thermostat order by focusing on nonresidential building consumption. Using our physical consumption. demand model for Greeley, revised to include the updated building census data, we will model the entire comimunity, assuming first $65^{\circ} \mathrm{F}$, then $70^{\circ} \mathrm{F}$ thermostat settings for all public buildings. The potential community energy savings for complete compliance as well as the actual savings for Greeley will be determined by comparison of the model results with the actually observed energy demand.

A second objective in reevaluating space heating energy demand in Greeley was the development and testing of a composite reference-physical model for community demand. As described in our proposal for the present contract period, the reference-physical or "hybrid" model will have application for simplified but accurate determination of the effects of community growth on community or regional demand for energy. This hybrid modelling procedure begins with the application of our statistical reference modelling technique to develop a weather dependent description of the existing mode of community energy demand for space heating. The input data requirements for our reference model are limited to daily values of measured community energy demand and spatially resolved meteorological data for each portion of the study area. When a community demand simulation of sufficient accuracy has been obtained, the hypothetical consunption for any number of new structures in any developmental configuration can be computed with the physical model. The demand predicted by the physical model is then added to the reference simulation to arrive at the total projected future supply requirements. Hence, the new building data developed to update our Greeley 
building census will be treated as a hypothetical growth scenario, modelled physicaliy, and added to the 1979-80 Greeley consumption simulation produced by our 1976-77 Greeley reference model. During the last half of the present contract period we will complete the preliminary development and testing of this hybrid model.

One additional application of our Greeley data sets and models involves comparative energy demand simulations using observed meteorological data as well as data derived from short-term (24-hour) weather forecasts. The analysis of the quality of energy demand forecasts based on. weather forecast data is the first step in the fulfillment of one of our original energy modelling objectives. To date, we have collected daily, 24-hour, maximum and minimum temperature and wind forecast information for Greeley from a local weather forecasting service. During the remainder of the contract period we will perform test simulations of daily consumption forecasts for several heating seasons. The use of 24-hour forecast data is also a useful test application for our sequential model updating technique which is discussed in Section 4.3.1.

We intend to eventually extend this consumption forecasting methodology to the maximum feasible forecast period. In this way we will determine the average and maximum energy prediction errors that would be associated with weather predictions from the best available short, intermediate and long-term forecasting technologies. We also hope to adapt the method to seasonal demand forecasts based on detailed analysis of historical meteorological data for weather trends during mild, normà and severe winters. 


\subsubsection{Modelling of Space Conditioning Loads During the Cooling Season}

The very detailed data base requirements and laborious computations for the best existing cooling models (fur example, ASHRAE, 1977 and NBSLD, 1976) prohibit their use in community or regional applications. Consequently; we are developing a model for simulating cooling energy demand with more simplified physical or, physical-reference hybrid procedures. The first step in developing an energy demand model for space conditioning is the identification, and validation of demand modules for individual buildings. This step requires the collection of detailed meteorological data (interior and exterior) for the various buildings being considered.

A previous attempt at modelling cooling demand was based on data collected for four large buildings in Fort Collins, Colorado during the summer of 1978. Results of the 1978 program were presented by Reiter et al. (1980). No physical modelling was attempted in the prior study. Rather, our statistical reference modelling procedure was applied to simulate the daily weather dependent energy consumption of these four buildings for air conditioning for 6 to 8 weeks of daily data. Whereas the results of this earlier study were not at all satisfactory, we were able to demonstrate considerable energy waste in some cooling systems. Also, we were able to identify critical weaknesses in our data and to design a more complete program for this year.

During the first week of June 1980, a field data collection program was initiated to compile information for the development and validation of building modules for space cooling energy denand calculations. Table 4.2.1 summarizes basic facts relating to the buildings being studied this summer. Three of the five structures have built-ill, central 
cooling systems. Building Number 4 has six separate cooling units, added one or two at a time as the building was expanded. Building Number 5 predatcs central air conditioning and is cooled by approximately 25 separate units of varying size and efficiency that were installed where and when needed. We feel that this rather limited sample is, nevertheless, quite broad-based in terms of diversity. The data derived from this study will also provide insights needed to effectively perform a greatly expanded data program next season.

\section{TABLE 4.2 .1}

\begin{tabular}{|c|c|c|c|c|}
\hline $\begin{array}{l}\text { Building } \\
\text { No. }\end{array}$ & $\begin{array}{c}\text { Age } \\
\text { (yrs.) }\end{array}$ & Sq. Ft. & Use & $\begin{array}{c}\text { Type of Cooling } \\
\text { System }\end{array}$ \\
\hline 1 & 13 & 70,000 & Office/Bank & Electric-Central \\
\hline 2 & 25 & 45,000 & Office/Bank & Gas-Central \\
\hline 3 & 15 & 70,000 & office/Bank & Gas-Central \\
\hline 4 & 15 & 25,000 & Office/Bank & Electric, Multi-Unit \\
\hline 5 & 60 & 130,000 & Office/Bank & Electric, Multi-Unit \\
\hline
\end{tabular}

Energy consumption in each of the buildings in Table 4.2.1 is being recorded at least twice daily, with hourly consumption observations from 6 A.M. until midnight available on occasional days, to determine detailed system responses to diverse weather. External weather data, including temperature, humidity, wind and solar radiation, are being collected nearby. Internal temperature and humidity are also recorded continuously in several of the buildings. Lastly, the internal heat loads, including lights, equipnent, and human metabolism are being determined for each building. 
This data program will continue until approximately August 30, 1980 or longer, depending upon the nature of the intervening weather. To date a very hot summer has provided good data for record-breaking peakdemand episodes. However, some contrasting cool and rapidly varying weather is needed for analysis of thermal storage effects in buildings.

During the latter portion of the contract period the building data and external meteorological data will be processed and combined to formulate building demand modules of cooling energy consumption. Reasonably accurate assessments of internal heat loads will allow modelling of the portion of the load that depends upon external weather. A simple physical model similar to the one used for individual building validations for the heating season will be adapted to the cooling model. A heuristic approach will be followed to characterize the operation and performance of the various air conditioning systems which we have encountered. Comparative analyses of the operating characteristics of these systems will then be performed to identify the critical parameters.

4.2.3 Development of an Energy Demand Model for Regional Applications An objective identified in our original proposal was the development of a model for simulating the weather-dependent energy demand of a large regional area. The impact of the severe winter of 1976-77 in the Eastern United States was cited as an illustration of the need for such a model.

We have chosen to develop and test our regional demand model by studying weather dependent energy consumption for the state of Colorado. This choice of location was based on proximity and because of the diverse climatological regimes occurring within the state. Approximately 
80 percent of the state is served by a single energy utility, the Public Service Company of Colorado (PSCC).

The north-south uriented Front Range of the Rocky Mountains divides Colorado into eastern and western slope areas. The effect of the 12$14,000 \mathrm{ft}$. mountains, is to channel the movement of, and greatly modify passing weather systems. Consequently, at many times the weather occurring in the eastern and western slope areas tends to be dissimilar. Thus, the service area of PSCC contains a wide range of simultaneous, intraregional demand variations comparable to those ordinarily encountered within a much larger geographical area.

The western slope portion of the PSCC service area, while relatively sparcely populated at present, is expected to be the center of considerable growth in association with projected shale oil development. This prospect makes the area ideal for application of our hybrid, physical-reference model. Also, the anticipated western slope development plus the diverse weather through the region provides the opportunity for applying a regional demand model to study intraregional energy transfers during periods of localized peak demand.

To date we have made some progress in gathering the very substantial volume of data required for development of our regional energy demand model. Our data needs include regional natural gas consumption information, adjusted to exclude gas used for industrial processes and disaggregated to show daily demand for the principal subregional areas. Discussions with PSCC officials have been positive. The utility company is interested in cooperating, provided that sufficient benefit can be realized to justify their efforts in preparing the data. However, PSCC 
has stated that the required data cannot be easily obtained for past heating seasons, but could be provided for the coming 1980-81 winter.

The second majur data requirement is regional meteorological. information. Through the State Climatologist's office at Colorado State University we have access to temperature data from approximately 120 stations, wind data from 20 stations, and insolation data from 12 stations reporting from locations within the PSCC service area. In addition, a portion of the Front Range region of Colorado is the designated study area for the Prototype Regional Observation and Forecast Service (PROFS) study. The PROFS program, being conducted by the Environmental Research Laboratory of NOAA in Boulder, Colorado, intends to develop improved short-term $(12-24 \cdot h r$.$) regional weather forecasts.$ PROFS is employing the most advanced observational and forecast technologies available in a four-year study program beginning this summer (1980). Front Range area meteorological data, collected by PROFS from satellites, radar, experimental sounding systems and from an array of specially instrumented surface weather stations, will be processed and archived daily' on the premises at the state climatologist's office. These meteorological data, which represent an area wherein more than 80 percent of PSCC's demand is located, will be immediately accessible to us for our modelling purposes.

We are now studying these data to identify the best combination of representative station locations for the PSCC service area. Where appropriate, urban weather effects will be superimposed on specific station data, using the urban climate model described in Section 3 of this report. 
The last and, to date, least successful regional data program is the determination of the spatial distribution of heated buildings within the PSCC servicc area. In our previous studies this information was obtained in the form of a detailed building census. These building census data were developed either through a house-to-house survey of the community, as in Greeley, or from computerized assessor's files, as in Minneapolis. We have consulted most assessor's offices within our regional study area and determined that nearly half of them do not have computerized files and cannot provide the specific data summaries we need. In the near future, we will present to PSCC a request for a summary of the number of gas customers for each postal zip code number within their service. area. If this information can be provided without undue effort, we will have made progress toward determination of the spatial distribution of the regional consumption. Further resolution of the structural composition of the heated buildings in the study area will then be made through application of statistical information derived for those areas wherein computerized assessor's files are available.

Several other programs discussed separately in this report present information relating to the development of our regional demand modelling capabilities. These include the development of a hybrid, referencephysical model (Section 4.2.2), the development of an urban climate model (Section 3.0), and the upgrading and reorganization of our data storage and manipulation procedures (Section 4.3.2).

\subsection{Recent Refinements of Demand Modelling Procedures}

We have made several modifications to our energy demand modelling procedures that have broad-based applications for improving their performance and usefulness. These refinements include a method for 
sequential: updating of our models to immediately accommodate new information as it becomes available. Also, two techniques for hypothesis testing in monitoring model performance, the performance confidence interval and the Kolmogorov-Smirnov goodness-of-fit test, have been adapted to our modelling procedure. For extending our modelling capability to regional areas we have revised and upgraded our data filing, retrieval and management system to handle greatly expanded masses of input information.

\subsubsection{Sequential Updating with the GMOH' Algorithm.}

The processes controlling energy demand for space conditioning of a community can be represented as a feedback-control-system. This concept has been described in an earlier report (Reiter et al., 1977) and is depicted in Fig. 4.3.1. In our prior studies we have also stressed the importance of an adaptive identification framework for accommodating ine complex evolution that can occur in a communities' energy demand in response to weather. Three types of changes or uncertainties that might influence community energy consumption are illustrated in Fig. 4.3.1. The first type of uncertainty directly affects the system dynamics through physical changes in the community. Examples of this type of change include the removal or addition of buildings and/or population. The second uncertainty reflects confusion or random adjustment signals being fed back from the system regulator. The regulator here is a combination. of physical mechanisin (e.g. automatically controlled furnaces) and human reaction (e.g. thermostat setting). The second uncertainty appears when new policies/regulations are enforced or new technologies/products are introduced. The third kind of uncertainty is introduced when the input variables change their course of occurrence, 


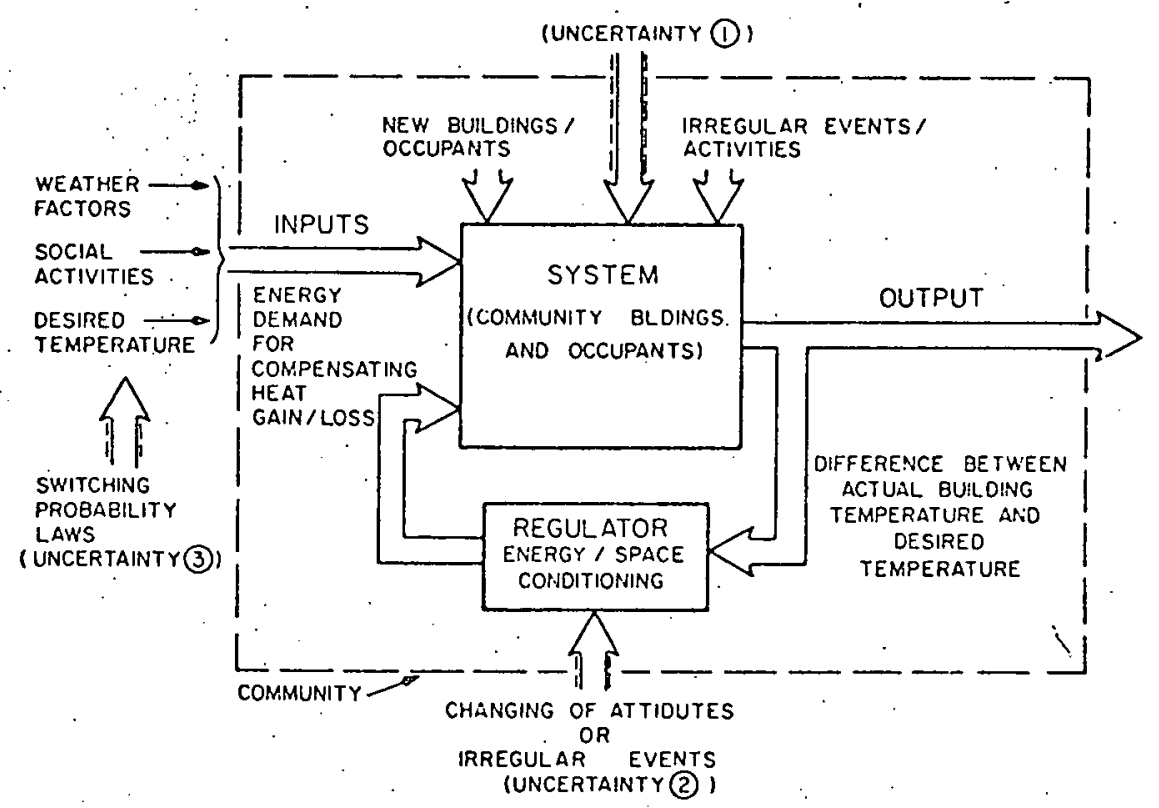

Fig. 4.3.1 Feedback-control-system realization of the conversion of energy to space-conditioning heeds. 
as with a change in the climate pattern of a region. Any one of these three elements catalyses the evolution of a community and makes any nonadaptive model become gradually obsolete.

To prevent a model from becoming obsolete with time it is necessary for our identification framework to perform two systematic operations: (1) It has to measure continuously the goodness-of-fit between the model and the real system; (2) it has to update sequentially the model with the latest acquired information. The blocks which provide such mechanisms are labelled MODEL UPDATING and HYPOTHESIS TESTING in our adaptive identification framework shown in Fig. 4.3.2. New procedures being incorporated in the HYPOTHESIS TESTING block are presented in section 4.3.2. Here we describe our procedure for sequential updating of the model using the GMDH algorithm.

To model a system for which data become available at regular time intervals, a sequential method of processing the data will produce a prediction of the system output at each interval using all of the data available up to that time. In the case of a space heating model, at each time step for which weather data are provided as input to the mode? and for which a prediction of energy consumption is made, the prediction is compared to the measured energy consumption and the model is updated using this information. This sequential method of data processing can also be useful in conjunction with batch processing methods. Coefficients which have been previously determined using a batch processing algorithm can be updated to include the new information when more data are available.

A fixed memory sequential algorithm may be used to predict the output of a slowly time-varying system. For a mdoel with a n-step 


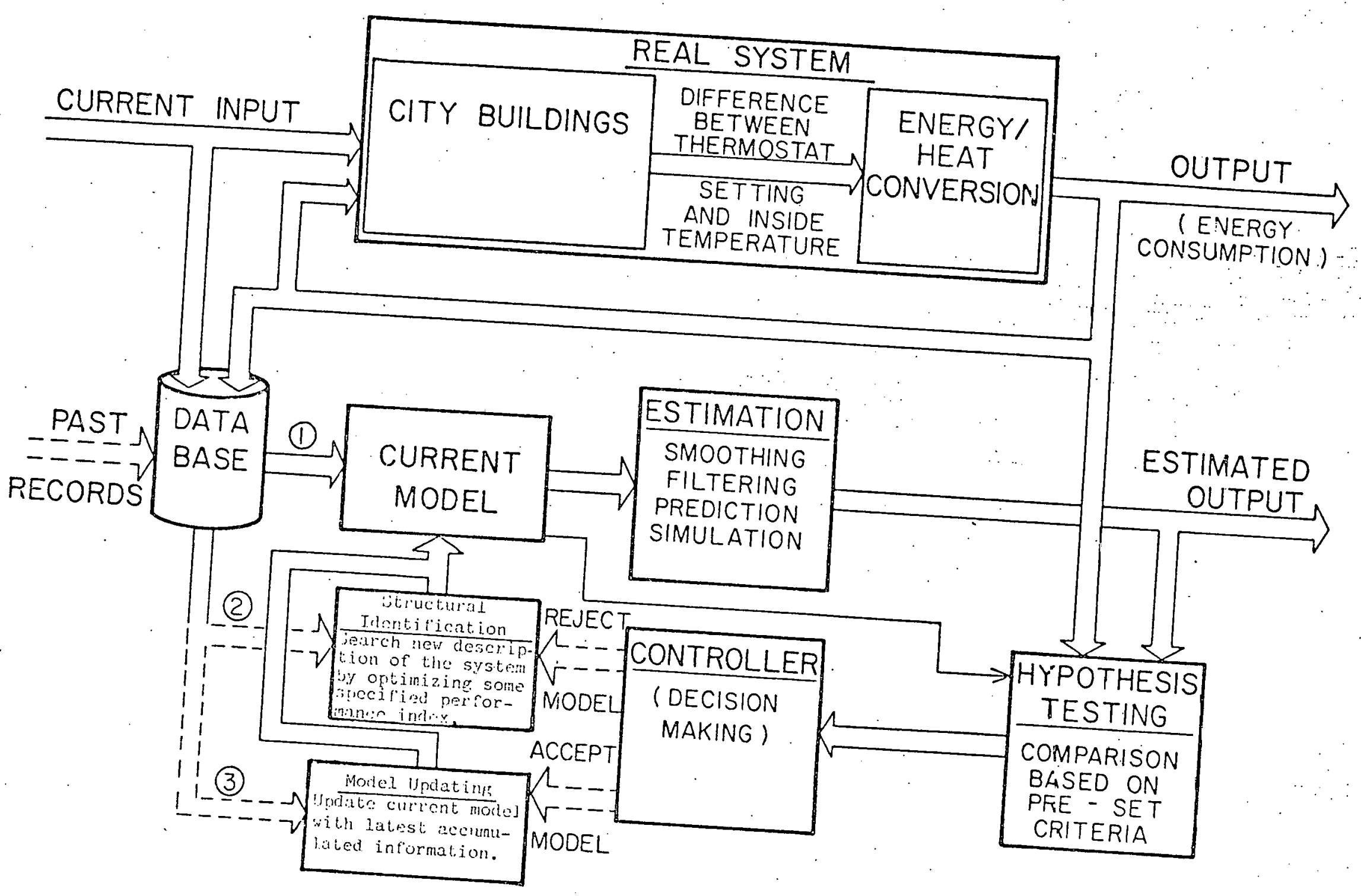

Fig. 4.3.2. The self-orgainzed dynamic forecasting model with adaptive
feedback, diagnostics, updating and reevaluation mechanisms. 
memory length, only the last $\mathrm{n}$ data points are used to predict the output of the system for the $n+1$ time interval. For each step, $k$, after the $n$ step, ilifurillation for the $k$ step is incorporated in the model and information from the $(k-n)$ step is deleted from the model.

Two methods of sequential estimation have been applied to the prediction of energy consumption for space heating. A sequentiạl GMDH, which can be used for updating coefficients in combination with our existing models, was developed and tested. The method of sequential ordinary least squares was also applied without using the GMDH. The method of sequential. least squares can be derived from the matrix equations for batch least squares by partitioning the matrices and applying the matrix inversion lemma.

Before processing the data sequentially, intitial values are required for the covariance matrix and coefficients. For a set of $n$ input variables the equation of least squares can be applied to at least $n$ points to give initial values. This method was used for the energy consumption model. Some other method would be needed if the first $n$ points are not available or the resulting matrix is not invertable.

The sequential GMDH requires an initial set of data to be processed in batch mode. The structure of the partial description is determined by this initial set and remains fixed. This set could be used as training as well as testing data to keep the length of data from the initial batch run as short as possible where length of the data source is a main concern. Corresponding to each partial description identified in the structure, a $3 \times 3$ matrix and three coefficients are stored. At each time step the coefficients evaluated at the preceeding step and the new input data are used to predict the system output. Next; the matrices and 
coefficients in the first layer are updated by sequential least squares and the estimates are used as input to the second layer. This process continues and all the coefficients are updated layer-by-layer.

Sequential least squares and sequential GMOH were applied to predict the energy consumption for space heating in the community of Greeley, Colorado. Figures 4.3 .3 and 4.3 .4 show the results of predicting energy consumption one day in advance given the weather input variables. The predicted values of energy consumption are close to the observed values. The RMS errors were 5.16 percent for $1975-76$ and 5.84 percent for 1978-79.

Four variables are used as input to the sequential least squares program. They are: average daily temperature, average daily wind speed, insolation, and a weekend and holiday index. If the system is stationary the coefficients multiplying the input variables will stay close to some fixed value. Figures 4.3 .5 and 4.3.6 show the variation of coefficients for the $1975-76$ and $1978-79$ seasons in Greeley. The system is most sensitive to temperature changes and the coefficient of this variable is quite constant over the $1975-76$ season. The coefficient of wind drops during periods of high winds. There is an uilexpected drop in the coefficient of wind during December 1978. For every other period the coefficient of wind is positive, which is expected, since heating loads due to infiltration increase with increasing wind speed. A close examination of the weather data for this period shows high winds occurring in phase with warmer temperatures. 


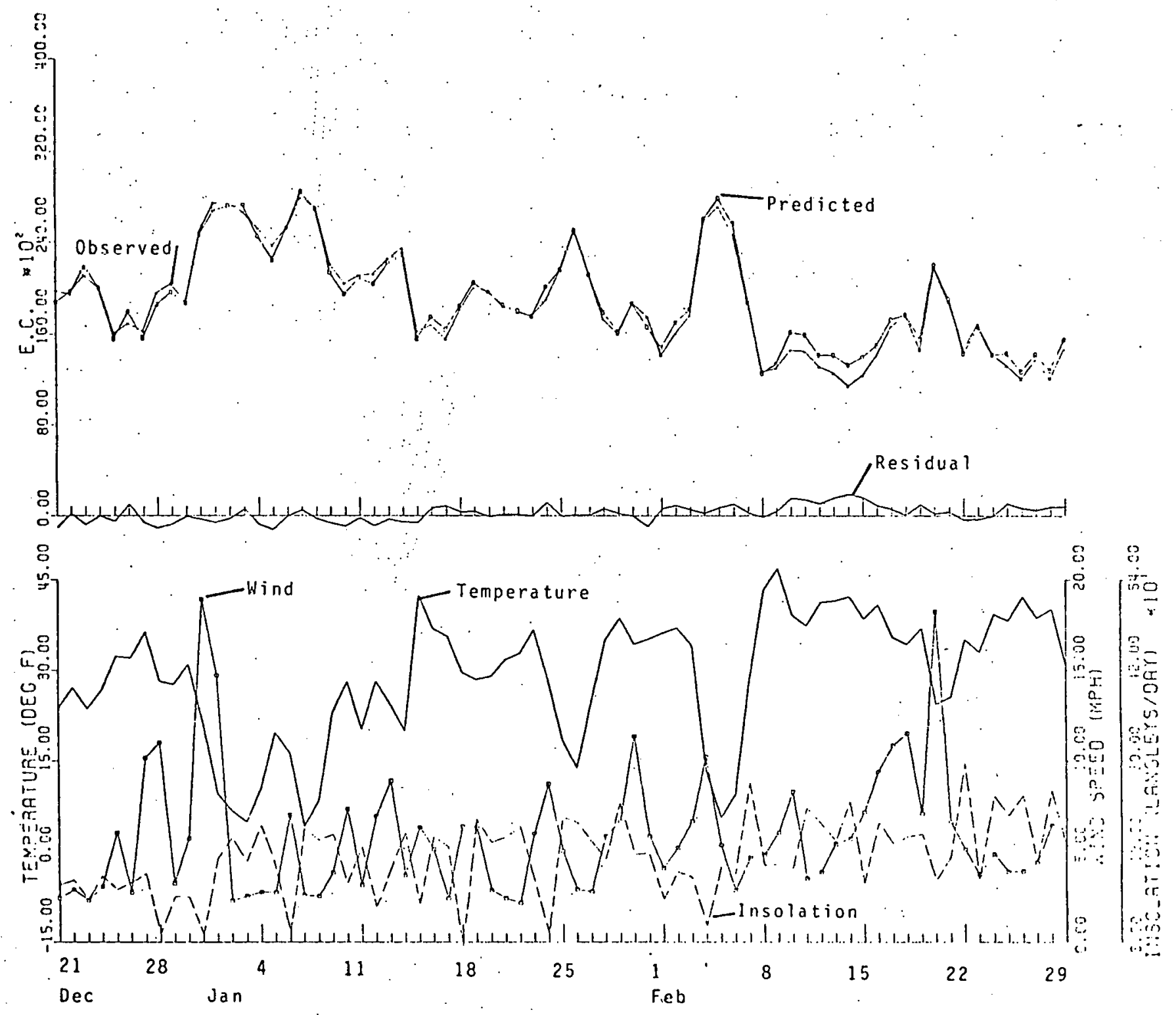

Fig. 4.3.3 Predicted natural gas consumption (MCF) for Greeley (197576) using sequential least squares with 20-day memory. 


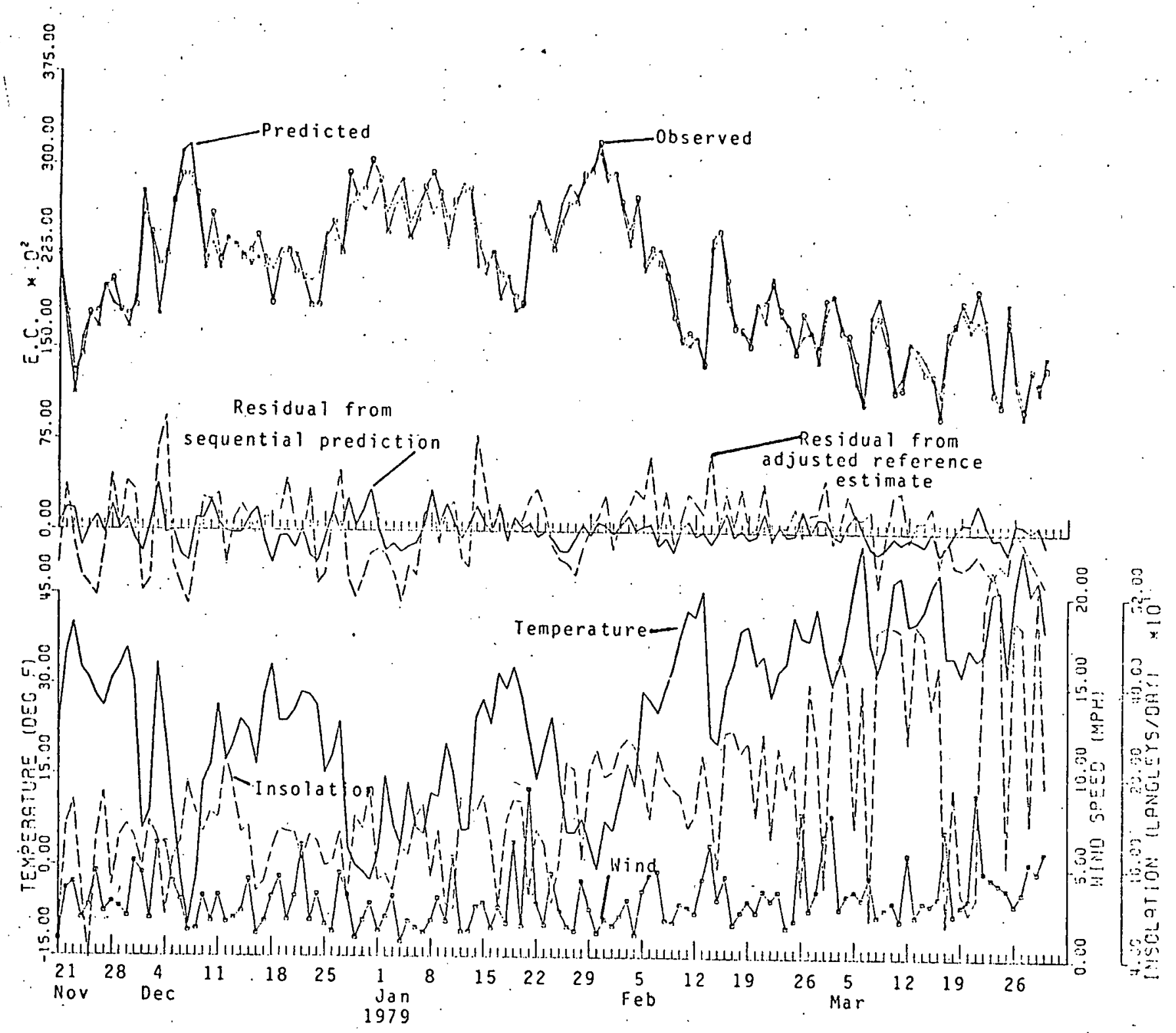

Fig. 4.3.4 Predicted natural gas consumption (MCF) for Greeley (197879) using sequential GMDH with a 30-day memory. The residual from the adjusted reference model is indicated for comparison. 


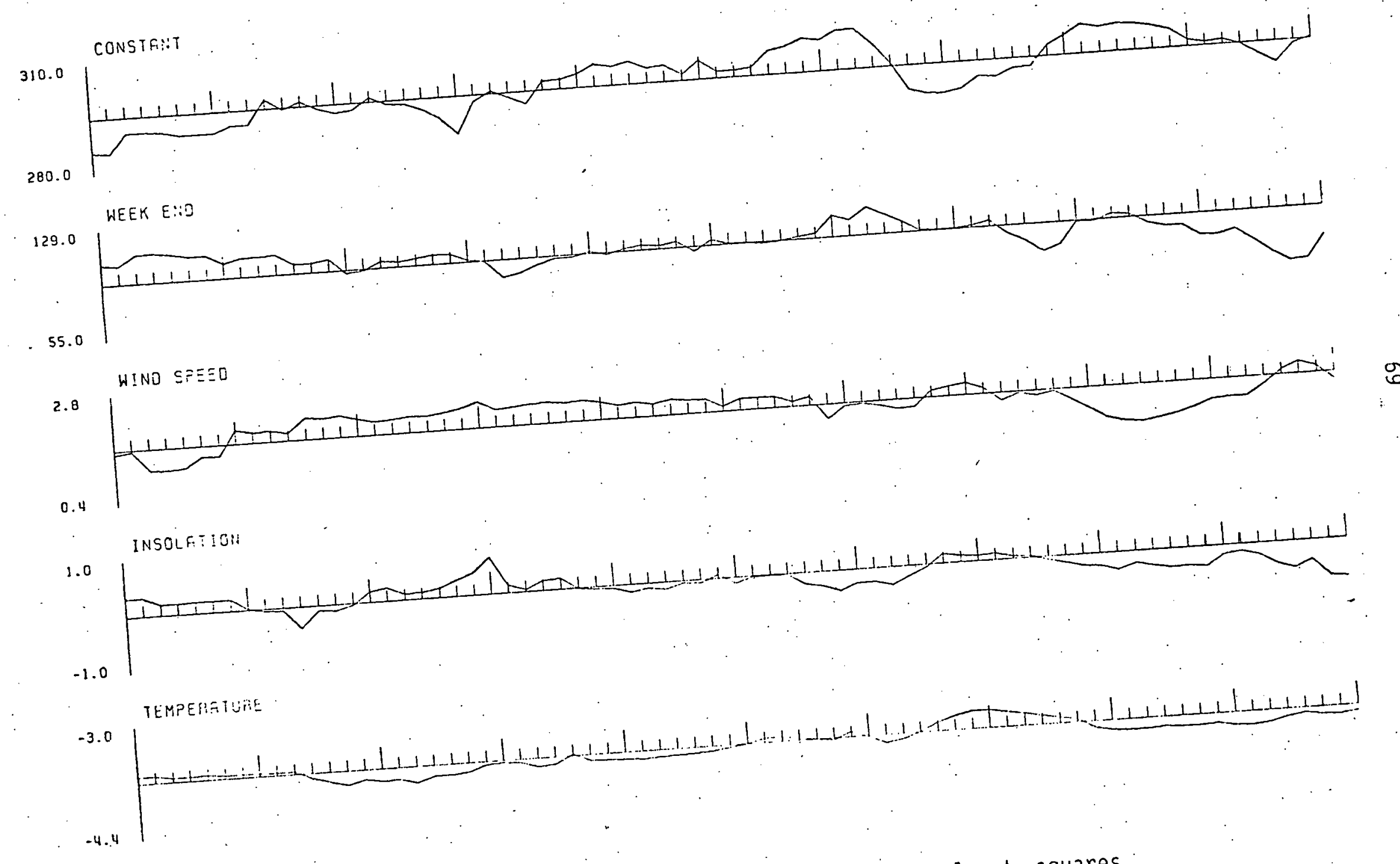

Fig. 4.3.5 Coefficients of variables from sequential
with a 30 -day memory for Greeley $(1975-76)$. 


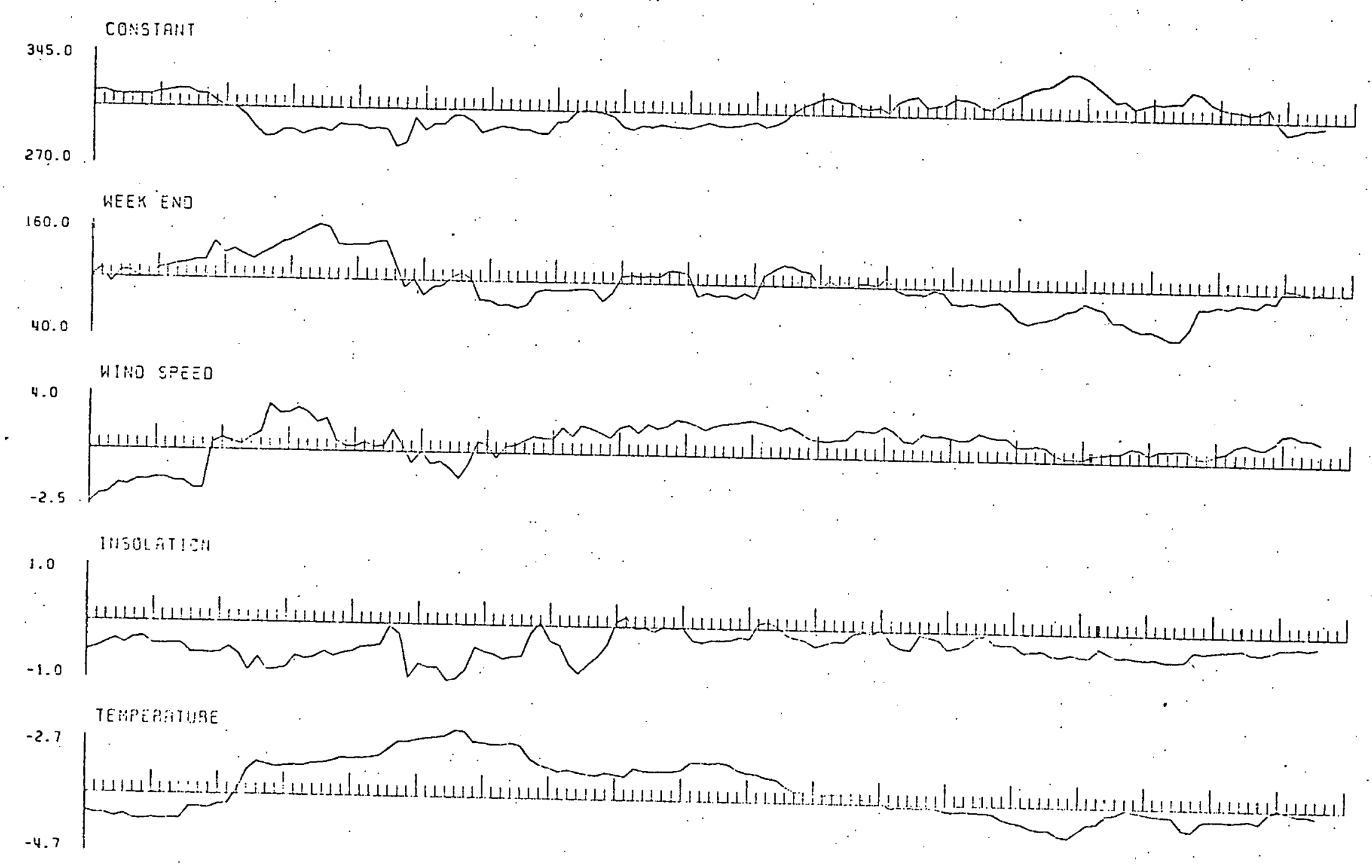

Fig. 4.3.6 Same as Fig. 4.3.5, but for 1978-79. 


\subsubsection{Refinement of the Procedure of Constructing a $(1-\alpha)$ Performance Confidence Interval}

One of the procedures used for the hypothesis testing portion of our model (Fig. 4.3.2) is the construction of a performance confidence interval for a given model. The performance confidence interval is derived from two concepts which, are prevalent in the fields of engineering and statistics, namely the perturbation and the confidence interval. A detailed discussion of this concept and its implications is given in Appendix $\mathrm{H}$.

\subsubsection{Improvement in Displaying the Goodness-of-Fit Test Between the CDF's of the Current System Response and the Incumbent Model Estimate.}

If model describes a system satisfactorily, the estimated response of the model will form a distribution (cdf) similar to that of the real system for the same time period, assuming stationarity. To check the validity of this assertion, one may compute the Kolmogorov-Smirnov statistics and evaluate the goodness-of-fit between the cdf's of the observed and the estimated responses. Such a procedure is known as the goodness-of-fit test or Kolmogorov-Smirnov test, and has been adopted as one means of evaluating the performance in our adaptive indentification framework.

The refined version of this test routine provides a graphic display of two cdf curves in one frame and computes the Kolmogorov-Smirnov statistics which give the maximum absolute deviation between two cdf's. This graph not only indicates the location of the Kolmogorov-Smirnov statistics but gives the user a visual indication of where any discrepency started, which range of the discrepancy is most severe, and which portion can be considered a good fit. 


\subsection{Upgraded Data File Retrieval/Archive Management System.}

In our computerized dynanic modelling framework there are five major types of computer files being operated either in batch mode or interactive mode through the CDC Cyber 720 computers at Colorado State University.

1. Modelling and simulation software. These include programs developed for identifying and optimizing the physical and statistical reference models, subroutineș for performance checking, error analys is and diagnosis, as well as a package designed for special algorithms such as the self-organizing identification GMDH algorithm and the sequential least-square updating algorithm.

2. Data displaying and tabulating software. These programs provide the user with the options either to check the output file of a job by printing it in a line-printed form by displaying it through the CRT screen, or by presenting it in a plotted graphic form.

3. Data/information extraction and generating software. These programs convert the raw data from one version to another, from hourly average to daily mean. They also condense a set of data into few statistical parameters, or interpolate, or smooth according to certain constraints.

4. Utility routines for programs execution and data files handling. These programs include various interactive and batch mode procedure files for processing disk file to tape file or vice versa; for generating source programs to object binary coded decks; for editing/ merging various source files into a collective library package, or for sorting/cataloging desired file(s) from the existing computer library package. 
5. Pure numerical or information data files. These include raw/ observed data, descriptive infornation, numerical output. files from different stages of estimalion and simulation.

For the purpose of minimizing the computer execution time, many program and data files have been maintained and stored in two versions the original coded version and the immediately accessible binary version. Security is insured by storage of most files on one master tape and one backup tape. The most current working files are maintained on disk space under our project account so that each file can be accessed either as a direct or an indirect file by the computer system depending on the length of the file.

The organization these computer files has become one of the mandatory tasks since our on-going modelling project has expanded from a suburban community to a metropolitan community and now to a large, statewide region. It is necessary to update all the related files in the current system from disk to tapes whenever changes of software occur, or new raw data sets are introduced. Consequently, all. these related (updated/new) files have to be named under a new version index or a complete new series of mnemonics so that in the latter stages the users can differentiate the new version from the old, or easily cross classify the data files with similar/common characteristics.

The number of files has mushroomed to a point that makes the development of a more efficient and systematic management of our computer files necessary in order to suit our expanding research objectives. To this end, we have taken two important steps to upgrade our data file retrieval/ archive handling system. First, a standardized mnemonic labelling procedure, proposed as a guideline for assigning names to new 
files, was designed. Secondly, two computer programs were coded and successfully tested with several primary options, namely for (1) creating a standard retrieval/archive procedure file to retrieve old files or to archive new files, (2) for generating a standard dumping/loading input control file for a subsequent job execution to transfer a file with standard description information to the designated storage space, (3) for updating information regarding all related files to a catalog description library, and (4) for executing the transaction of files according to the procedures and control parameters specified by (1) and (2).

A brief technical description of the Mnemonic System and of the Retrieval/Archive Mạnagement System follows.

\section{Permanent File Mnemonic}

for

Community Energy Consumption Modelling

To facilitate the identification of computer data and program files a system of mnemonics has been proposed. The system adopts a sevencharacter mnemonic labeling procedure for numerical files and letter combination mnenonics for program and procedure files as explained below. This system may not completely isolate the information being located. Proper identification can only be assured by examination of the file header cards. The header cards should consist of 5 records (lines) describing the file, its type, purpose and any other helpful comments.

From this date on it will be assumed that these guidelines for file identification will be adhered to. Whenever appropriate. The file name mnemonics should be relied upon to converge to a range of file 
possibilities wherein the desired information may be located." This system; assisted by conscientious utilization of header card space during file creation, should allow the users to process information quickly and accurately.

NUMERICAL FILE MNEMONIC

The following guidelines should be followed for labeling all accourt, library and archived perillallent numerical files.

Column

Number

1: Community: $G=$ Greeley, $C=$ Cheyenne, $M=$ Minneapolis, $R=$ Region

2, 3: File type identifier: see legend below - 2 characters

4 Year: last digit of year of first data point. 5, 6, 7, etc.

5. Version: $1,2,3$, etc.

6. Numerical types: $D=$ Data, $C=$ Coefficients, etc.

7. Format: $C=$ Coded, $B=$ Binary, or character to differentiate two similar files, e.g. 1, 2, 3, etc.

File type identifier legend

a) First character

$E=$ Energy, $W=$ Weather,$P=$ Predicted

b) Second character

$0=$ Observed

$P=$ Physical reference; $E=$ Physical residual, $F=$ Adjusted physical reference

$S=$ Statistical reference $R=$ Statistical residual, $A=$ Adjust ed statistical reference

$U=$ Updated (sequential least squares)

c) Combinations

$\mathrm{GM}=\mathrm{GMDH}(\mathrm{I} \& \mathrm{II})$

$F R=$ Forecast - GMDH (III)

SQ = Sequential - GMDH (IV)

$I B=$ Individual building

$C R=$ Confidence region

Examples:

GE0810C = Greeley, $E C$, observed, 1978, version 1, data, coded.

MFR61CB = Minneapolis, forecast, 1976, version 1, coefficients, binary.

CPE9101 = Cheyerne, predicted, physical residual, 1979, version, data, 1. 


\section{PROGRAM AND PROCEDURE FILE MNEMONIC}

The following guidelines should be followed for labeling all account, library and archived permanent program and procedure files.

File name may be of a character of unspecified length ( 7 characters or less) with the following:

a) File name terminators.

$$
\begin{aligned}
P G & =\text { Program } \\
D F & =\text { Day file } \\
\text { GO } & =\text { General procedure file (JCL) } \\
T J & =\text { Tape job } \\
\text { LIB } & =\text { Library } \\
\text { OUT } & =\text { Output } \\
\text { PACK } & =\text { Package }
\end{aligned}
$$

b) File name initiator - version number (1, 2, 3, etc.) or version. letter $(B=$ Binary or compiled)

Examples:

$$
\begin{aligned}
& \text { GMDHPG }=\text { GMDH program } \\
& \text { GMDHDF }=\text { GMDH day file } \\
& \text { 3DATALIB }=\text { Data library version } 3 \\
& \text { BSUBLIB }=\text { B Bnary subroutine library } \\
& \text { UDUMPTJ }=\text { UDUMPIT tape job for dumpilig files to tape } \\
& \text { ULOADTJ }=\text { ULOADIT tape job for retriving files from tape. }
\end{aligned}
$$

\section{Retrieval/Archive Management System}

The retrieval/archive management system is a software package designed to facilitate the orgainzation and maintenance of a large number of computer library files. Convenience in manipulating, documenting, archiving and maintaining all information contained within the archive library is provided through available options which allow the user to readidly and accurately categorize any designated library file.

The archive management system is easily implemented through the computer terminal by the execution of a single command. This command sets the system into action as the terminal begins to ask a series of questions which allow the user to identify the tape volume number, tape password, and archive catalog identifier code. Once this information has been 
entered into the terminal keyboard the archive system responds with available options which allow the user to select the archiving tasks he wishes to accomplish. These tasks include the tollowing:

1) Initializing a tape for archiving library files.

2) Archiving new files and documenting the file with user-supplied information which identifies the file, its type, purpose, related files and comments about the file.

3) Archiving old files so that corrections can be made to versions that have already been documented without changing the documentation catalog entry for the file.

4) Retrieving files by entering the file name and at the same time loading all related files specified in the archive documentation catalog.

5) Cleaning the archive tape by removing incorrect versions of files and old archive documentation catalogs.

Finally, it should be noted that all applicable archiving options can be applied to the library files maintained in the user's accolint so that a catalog of information is available for account files as well.

After the user has interactively completed the procedure for his specific archiving task, the second and final step of the archiving management system is begun. This step involves a simple procedure which will load and execute the archive system subnit file. The user needs only to insure that the submit file contains a current valid account number. If this requirement is satisfied, the archive system automatically executes all of the options which the user has designated during the interactive portion of the procedure. After the submit file has been executed, the user simply waits until his tape is loaded at the main computer site and 
the archive management system provides him with an updated and documented archive library of all his files.

MANUPULATION INSTRUCTION

A. Tape Initialization

In the Batch subsystem execute the procedure file as follows:

1. CALL, ARCHGOI (or - ARCHGOI) which executes the following commands: GET, BARCHI

BARCHI

REPLACE, CMDFIL, ARCHGO.

Key in the proper response to the prompt (?) given during execution of BARCHI.

Example: VSN-0A2448
a) Password - LEONG
b) Code - AA
c) Current Catalog - T
d) New Catalog - T
e) Choose option (5) Tape Initialization END BARCHI

2. OLD. ARCHSM.

3. SUBMIT, ARCHSM, B. - executes ARCHGO.

B. ARCHIVE New Files

1.: Same as (A) up to 1-e - Choose option 1

File Name? (Max. 7 char.)

File Type? (Max. 30 char.)

Related Files? (Max. 80 char. $=1$ rec.)

Purpose? \{Max. 15 standards - (not implemented) input "S" RETURN Index Number? 1-15 or choose 16 for a list of current standards

2. To terminate purpose or comments input, key in RETURN key or type END.

3. After all files have been documented choose option 0 or use RETURN.

4. OLD, ARCHSM

5. SUBMIT, ARCHSM, B (for tape jobs)

C. Archive 01d File - choose option 2 and use same procedure as above replaces previous copy of file. 
D. Retrieve Files - choose option 3 and use procedure above - (max. 200 files/load).

E. Clean Tape - choose option 4 - removes old copies of files from tapes - must have an empty account permanent file library to execute use same procedure as above. 
5. Stimulating Residential Energy Conservation Through the Financial

Sector

This part of the project was designed to explore new methods of involving Financial Institutions in the drive to reduce residential energy use. The concept was introduced in last year's final report to DOE (Reiter et al., 1980). It involves a change of the traditional formula used by leading instituliuns. Normally Savings and Loans require that a prospective home buyer earn approximately four times the sum of payments to principal, interest, taxes and insurance. With energy costs rising dramatically since 1973, these too could be included in the qualifying formula. In so doing the prospective buyer would be better appraised about the energy requirements of different homes. More important, he/she would be given information regarding potential tradeoffs between the cost of conservation measures and subsequent energy savings. The entire procedure is now being designed including the development of interactive microcomputer programs for use in the lending institutions.

One of the first tasks in the research was to contact the major energy think tanks ${ }^{1}$ in order to find out what currently was available along these lines described above. The following summarizes the major conclusions emerging from these interviews:

1. Only a small percentage of the banking community actively promotes energy conservation in their lending activities.

\footnotetext{
1 Individuals at Lawrence Livermore, Brookhaven, Oakridge, and Los Alamos were contracted initially; this led to other contacts at DOE, architectural firms, the Savings and Loan League, the Federal Home Loan Bank Board, the Farner's Home Administration and individual progressive banks.
} 
2. Banks do not seem to be concerned about default on mortgages. There appears to be general agreement that consumer installment debt would be al risk, not home loans.

3. The average loan to retrofit a home is approximately $\$ 750$. Bankers argue that the transactions cost to make such small loans make this form of business unprofitable. Contrast this with the average home improvement loan, $\$ 15,000$.

(An innovative way of reducing transactions cost is for home installers to package loans and seek financing for the entire package. This strategy. will be evaluated in the final report.)

4. (2) and (3) are enough to explain (1). If conservation could be shown to be a profit center, then banks would actively promote it. The final report will review alternative ways to either reduce transaction costs or increase the profitability of conservation.

5. Three or four computer routines now exist to evaluate the economic efficiency of alternative conservation practices. Many of them are restricted to active and passive solar designs. Some are designed for hand held calculators, others for central computers. Both of these provide a foundation for the microcomputer programs envisaged in this project but do not duplicate them.

6. A data base to make the program operational is not yet available. The BECA project at Lawrence Livermore should help alleviate this deficiency. Alternative methods of collecting the needed data and storing them at banks or at the 
Society for Real Estate Appraisors will be assessed in the final report.

7. A point system for use by lenders and builders has been successfully implemented in Denver. However; it is restricted to new construction. Another drawback is that the points do not allow the buyer to evaluate potential tradeoffs in terms of dollars. Pacific Gas and Electric of California is experimenting with a program whereby interest-free loans would be granted to homeowners who wish to retrofit. A lien is placed on the property and the utility is paid the interest cost upon sale. A. similar program has been implemented in Portland. It is interesting to note that such efforts only accelerated after the utilities realized that conservation was a viable profit center for the company. Given the rapidiy accelerating peak load generating costs, they began to turn attention to peak shaving measures.

The final report will build on these findings and observations. It will include a set of interacting microcomputer programs tajlored to the reeds of the financial sector. In addition, it will analyze ways in which receptivity to such programs could be improved. Finally, a mechanism for developing a data bank will be presented. 
References

American Society of Heating, Refrigeration and Air Conditioning Engineers (ASHRAE), 1977: Handbook of fundamentals.. ASHRAE, New York, NY.

Arkin, P.A., 1979: The relationship between fractional coverage of high cloud and rainfall accumulations during GATE over the B-scale array. Mon. Wea. Rev., 107, 1382-1387.

Baker, D.G., 1969: Frequency, duration, commencement time and intensity of temperature inversions at St. Paul-Minneapolis. ‥ Appl. Met., 8, 747-753.

Bowling, S.A., 1978: A study of the subarctic heat island at Fairbanks, Alaska. EPA-600/4-78-027.

Carlson, T.N. and F.E. Boland, 1978: Analys is of urban-rural canopy using a surface heat flux/temperature model. ‥ Appl. Met., 17, 998-1013.

Cheng, C.-P. and R.A. Houze, Jr., 1979: The distribution of convective and mesoscale precipitation in GATE radar echo patterns. Mon. Wea. Rev. , 107, 1370-1381.

Ciesielski, Paul E., 1980: Variability within the ocean-atmospheric system over the North Pacific. Colorado State University, Environmental Research Paper No. 25, in press.

Danielsen, E.F., 1980: Stratospheric source for unexpectediy large values of ozone measured over the Pacific ocean during Gametag, August 1977. ‥ Geoph. Res., 85 (C1), 401-412.

DeMarrias, G.A., 1961: Vertical difference observed over the urban. area. Bul. Amer. Met. Soc., 42, 548-554.

Ding, Yi-Hui and Elmar R. Reiter, 1980a: A preliminary study on the variability in the frequency of typhoon formation over the West Pacific ocean. Colorado State University, Environmental Research Paper No. 22, 21 pp.

and , 1980b: A preliminary study of the variability in the frequency of typhoon formation over the West Pacific ocean. Submitted to Mon. Wea. Rev. for publication.

and 1980c: A further study of the variability in the frequency of typhoon formation over the West Pacific ocean. Colorado State University, to be published as Environmental Research Paper No. 27:

and 1980d: A study of the variability in the frequency of typhoon formation over the West Pacific ocean. To be' submitted to Archiv. fuer Meteoro. Geo. and Bioclim. 
Edson, Roger T., 1980: Parameterization of net radiation of the surface using data from the Wangara Experiment. Colorado State University, Environmental Research Paper No. 26, in print.

Leahey, D.M., 1975: An application of a simple advective pollution model to the city of Edmonton. Atmos. Environ, , 9 , 817-823.

and J.P. Friend, 1971: A model for predicting the depth of the mixing layer over an urban heat island with application to New York City. ‥ Appl. Met., 10, 1162-1173.

Middleton, John W., 1980: A cross-spectral study of the spdlial relationships in the North Pacific sea-surface temperature anomaly field. Colorado State University, Environmental Research Paper No. 23 , in print.

Murakami, M., 1979: Large-scale aspects of deep convective activity over the GATE area. Mon. Wea. Rev., 107, 994-1013.

National Bureau of Standard, 1976: NBSLD: The computer program for heating and cooling load in buildings. NBS Building Science Series 69, U.S. Government Printing Office, Washington, D.C. 20402.

Newel1, R.E., D.G. Vincent and J.W. Kidson, 1969: Interhemispheric mass exchange from meteorological and trace substance observations. Tellus, 21, 641-647.

Reeves, R.W., C.F. Ropelewski, and M.D. Hudlow, 1979: Relationships between large-scale motion and convective precipitation during GATE. Mon. Wea. Rev. , 107, 1154-1168.

Reiter, Elmar R., 1978: Impact of stratospheric ozone on tropospheric concentrations. In: Air Quality Meteorology and Atmospheric Ozone. ASTM STP653, A.L. Morris and R.L. Barras, Eds., American Society for Testing and Materials, pp. 506-519.

, 1979: On the dynamic forcing of short-term climate fluctuations by feedback mechanisms. Colorado State University, Environimental Research Paper No. 21, 62 pp.

1980a: Energy consunption modelling. Paper presented at Workshop "The Economic Impact of Climate", April 11-12, 1980, Columbia, MO. , 79 pp.

, 1980b: Planetary-wave behavior and arctic air pollution. Paper presented at Graduate School of Oceanography, University of Rhode Island, Kingston, R. I. 35 pp.

1980c: Trip report to U.S. Department of Energy and National Science Foundation on trip to China/Tibet. (To be prepared).

E. Baver and S.C. Coroniti, 1975: The natural stratosphere of 1.974. CIAP Monograph 1. U.S. Dept. of Transportation, Washington, D.E. 20590. 
and $Y_{i-H u i}$ Ding, 1980: The role of the Qinghai-Xizang Plateau in feedback mechanisms affecting the planetary circulation. Paper presented at the Symposium on Qinghai-Xizang (Tibet) Plateau, May $25-31,1980.59 \mathrm{pp}$.

C.C. Burns, H. Cochrane, G.R. Johnson, H. Leong, J. McKean, J.D. Sheaffer, A.M. Starr and J. Webber, 1980: The effects of atmospheric variability on energy utilization and conservation. Colorado State University, Environmental Research Paper No. 24, 103 : pp.

Riehl, H., 1977: Vertical distribution of energy transfer and radar echo tops in the equatorial trough zone. Mon. Wea. Rev., 105, 230-231.

Spera, D.A. and T.R. Richards, 1978: A revised wind shear power law model. Wind Energy. Project Office, Project Information Release No. 70, National Aeronotic and Space Administration.

Thompson, R.M., Jr., S.W. Payne, E.E. Recker and R.J. Reed, 1979:

Structure and properties of synoptic-scale wave distribution in the intertropical convergence zone of the eastern Atlantic. 3 . Atmos. Sci. 36, 53-72.

Vincent, D.G., 1968: Mean meridional circulation in the northern hemisphere lower stratosphere during 1964 and 1965. Quart. J. Roy. Meteor. Soc., 94, 333-349. 